\author{
Michał Fiedorowicz', Ewa Bartnik ${ }^{2,3}$, Paweł Sobczuk ${ }^{4,5}$, Paweł Teterycz ${ }^{4}$, Anna M. Czarnecka ${ }^{1,4}$ \\ ${ }^{1}$ Department of Experimental Pharmacology, Mossakowski Medical Research Centre, Polish Academy of Sciences, Warsaw, Poland \\ ${ }^{2}$ Institute of Genetics and Biotechnology, Faculty of Biology, University of Warsaw, Poland \\ ${ }^{3}$ Institute of Biochemistry and Biophysics, Polish Academy of Sciences, Warsaw, Poland \\ ${ }^{4}$ Department of Soft Tissue/Bone Sarcoma and Melanoma, Maria Sklodowska-Curie Institute — Oncology Centre, Warsaw, Poland \\ ${ }_{5}^{5}$ Department of Experimental and Clinical Physiology, Warsaw Medical University, Warsaw, Poland
}

\title{
Molecular biology of sarcoma
}

\author{
Address for correspondence: \\ Anna M. Czarnecka, MD, PhD \\ Klinika Nowotworów Tkanek Miękkich, \\ Kości i Czerniaków \\ Centrum Onkologii — Instytut \\ im. Marii Skłodowskiej-Curie \\ ul. Roentgena 5, 02-781 Warszawa \\ Phone: +48 225462027 \\ Fax: +48226439375 \\ e-mail: am.czarnecka@coi.pl
}

Oncology in Clinical Practice

2018, Vol. 14, No. 6, 307-330

DOI: $10.5603 / \mathrm{OCP} .2018 .0045$

Translation: dr n. med. Dariusz Stencel

Copyright () 2018 Via Medica

ISSN 2450-1654

\begin{abstract}
Soft tissue sarcomas are a large group of heterogenous neoplasms, many of them are highly aggressive. Most of the cases are sporadic, without any well-defined pathogenetic factor. Potential risk factors are ionizing radiation, lymphatic oedema (secondary angiosarcoma of the breast), viral infections (HHV8 and Kaposi sarcoma), exposure to chemical factors (vinyl chloride and hepatic angiosarcoma). Genetic susceptibility plays a role in a minority of cases. However, mutations in TP53, ATM and ATR genes are associated with enhanced susceptibility to radiation. Li-Fraumeni syndrome (autosomal dominant TP53 mutation) predisposes to development of malignancies, one third of them are sarcomas. Genetic alterations observed in sarcomas could be divided into three major groups characterized by: (1) chromosome translocations; (2) simple karyotype and mutations; (3) variably complex karyotypes. A large part of sarcomas belong to the first group and the specific chromosal translocations could be utilized in the diagnostic process. A smaller number of sarcomas could be assigned to the second group, e.g. desmoid fibromatosis (CTNNB1 or APC mutations) and GIST (KIT, PDGFRA, or less frequently BRAF, SDH, $N F 1$ ). A large number of sarcomas are characterized by complex and variable karyotypes. Gene copy number alterations are frequent in this group, e.g. in well-differentiated liposarcoma there is an amplification of MDM2, CDK4 and HMGA2 genes or sarcoma-specific chromosomal break regions present in the $\mathrm{CHOP}$ gene in myxoid liposarcoma and FKHR in alveolar rhabdomyosarcoma.

Key words: sarcoma, genetics, STS
\end{abstract}

Oncol Clin Pract 2018; 14, 6: 307-330
Soft tissue sarcomas account for a large group of heterogeneous mesenchymal tumours, which constitute about $1 \%$ of solid tumours in adults. Many of them are very aggressive, so they are responsible for disproportionately more malignancy-related deaths in young adults than cancers. Their typical classification is based on the similarity to healthy mesenchymal tissues to which the type of specific sarcoma is the closest. The term soft tissue sarcoma includes more than 70 types, and primary sarcoma consists of 12 basic types, which differ in terms of pathological and clinical features $[1,2]$.

In the vast majority of cases, sarcomas occur sporadically, without a clearly defined factor underlying tumorigenesis. Possible risk factors include exposure to ionising radiation, lymphoedema (breast angiosarcoma), viral infections (HHV8 - Kaposi sarcoma), or exposure to chemical agents (vinyl chloride - liver angiosarcoma) [2].
Mutations in genes TP53, ATM, and ATR are associated with increased sensitivity to ionising radiation and subsequent development of sarcomas [3]. In $10 \%$ of patients with type 1 neurofibromatosis (NF1, mutation in the gene encoding neurofibromin 1) gastrointestinal stromal tumours (GIST) as well as malignant peripheral nerve sheath tumours (MPNST) develop. Li-Fraumeni syndrome (autosomal dominant mutation in the TP53 gene encoding p53 tumour suppressor protein) predisposes to the development of malignant tumours, one third of them are sarcomas. Other syndromes that predispose to the development of sarcomas are Gardner syndrome (desmoid tumour), Werner syndrome (soft tissue sarcomas), Bloom's syndrome (osteosarcoma), Beckwith-Wiedemann syndrome (rhabdomyosarcoma), and Costello syndrome (rhabdomyosarcoma). Some of the spindle cell sarcomas (SCSs) are present during the 
course of other diseases, for example osteosarcomas during Paget's disease or chondrosarcomas during multiple cartilage-capped bony excrescences [2, 4-6].

Recent studies on a group of 1162 patients with sarcomas suggest other genetic risk factors, such as $B R C A 2$, $A T M, A T R$, and ERCC2 gene damage [3]. The early phase research centre MD Anderson Cancer Centre carried out an analysis of potential mutations in patients with soft tissue sarcomas, i.e. 102 consecutive patients directed to this centre were tested using the Foundation Medicine (FoundationOne) test based on next-generation sequencing (NGS). The study included a panel of 315 genes for which targeted drugs are established. Most commonly the mutations were found in TP53 (31.4\% of patients), $C D K 4$ (23.5\%), MDM2 (21.6\%), RB1 (18.6\%), and $C D K N 2 A / B(13.7 \%)$ genes. Interestingly, $50 \%$ of patients receiving treatment based on the result of the test $(16 \%)$ achieved stable disease (SD). Of the 102 patients in the examined cohort, $40(39 \%)$ were characterised by either no known mutation (7\%) or no mutation currently recognised as the target of the available drug (32\%). The remaining $62(61 \%)$ patients had mutations potentially allowing the use of targeted therapy. Fourteen (14\%) patients had lesions that could be used for treatment with the medicinal products registered for sarcoma treatment. There were cases of treatment with pazopanib or imatinib, which included five patients with the $P D G F R$ mutation (1 GIST), four with the FGFR mutation, three with the KIT mutation (2 GIST), and two with the KDR gene aberrations [7]. Due to the high heterogeneity of sarcomas one should expect a very wide spectrum of genome damage but also numerous epigenetic changes.

Generally, the genetic changes observed in sarcomas can be divided into three groups:

- chromosomal translocations;

- point mutations without changing the karyotype;

- the presence of a variable and complex karyotype;

The sarcomas characterised by the presence of the first group of lesions (translocations) include a significant proportion of sarcomas. Occurrence of translocations is used for diagnostic purposes (Tables $1,2)$. A smaller number of cases could be included in the group of the second type of defects (point mutations), for example desmoid tumour (CTNNB1 or $A P C$ gene mutations) or GIST (KIT or PDGFRA mutations, significantly less $B R A F, S D H, N F 1)$. Finally, a large proportion of sarcomas are classified as the third type of lesion, which are characterised by a complex and variable karyotype. In these tumours, the number of gene copies may be much higher, such as in differentiated liposarcomas, in which the amplifications of the $M D M 2, C D K 4$, and $H M G A 2$ genes are observed. Typical chromosomal damage can also occur, such as in CHOP gene in myxoid liposarcoma and FKHR gene in alveolar rhabdomyosarcoma.
Recently published genomic research of the Cancer Genome Atlas Research Network (https://cancergenome.nih.gov/) [8] included a genetic analysis of 206 tumours of six major types of adult sarcomas. There were five tumours with complex karyotype: (1) dedifferentiated liposarcoma (DDLPS ), (2) leiomyosarcoma (LMS), (3) undifferentiated pleomorphic sarcoma (UPS), (4) myxofibrosarcoma (MFS), (5) malignant peripheral nerve sheath tumour and sarcoma with a relatively simple karyotype, and (6) synovial sarcoma, in which a single chromosomal translocation $\mathrm{t}(\mathrm{X} ; 18)$ (p11;q11) is typically observed. In contrast to tumours of epithelial origin, the examined sarcomas (with the exception of synovial sarcoma) are characterised primarily by changes in the number of gene copies, with a small overall number of point mutations (insertions, deletions, missense mutations). A high number of mutations occur in only a few genes (TP53, ATRX, RB1), which are "repeated" in many types of sarcomas. For example, while $M D M 2$ amplification was present in all DDLPS, deletions in TP53 were found in 9\% of LMS, $16 \%$ of UPS, and $12 \%$ of MFS. In RB path, RB1 deletions were detected in $14 \%$ of LMS, $16 \%$ of UPS, and $24 \%$ of MFS; and CDKN2A deletions (p16) in $8 \%$ of LMS, $20 \%$ of UPS, and $18 \%$ of MFS. The disturbances of the RB pathway also included $C D K 4$ amplification in $86 \%$ and $C D K N 2 A$ deletions in $2 \%$ of DDLPS. Generally, it has been shown that the total number of somatic mutations in the aforementioned types of sarcomas are relatively low (1.06 per $\mathrm{Mb}$ ); however, $67 \%$ of tumours carried mutations previously known as potentially oncogenic. The highest mutation burden was identified in DDLPS and MPNST, mostly C $>$ T mutations in the $\mathrm{CpG}$ islands. Only $12 \%$ of the tumours had elongated telomeres. A significant role in tumour progression of sarcomas may be played by specific changes in the DNA methylation pattern and regulation via miRNA. In these studies, JUN gene amplification was identified as a potential marker for shorter survival and a putative therapeutic target in the subgroup of DDLPS sarcomas. Although it has been found that uterine LMS (ULMS) and soft tissue LMS (STLMS) are molecularly distinct, inhibitors of the PI3K-AKT-mTOR signalling pathway may have potential application in the treatment of both sarcoma groups. STLMS were characterised by the activation of the HIFIa and IGF1R pathway, cell cycle (CCNE2 - G1/S-Specific Cyclin-E2), DNA replication (MCM2 - minichromosome maintenance complex component 2), and DNA repair (FANCI - Fanconi anaemia group I protein) deregulation, while ULMS were mainly affected by DNA repair (ESR1 — oestrogen receptor 1) disturbances. Finally, molecular analyses have shown that UPS and MFS are tumours with the same cellular origin (a common type of progenitor cell) that have different numbers of mucosal components, 
Table 1. Genetic fusions in soft tissue sarcoma (modified, reprinted with permission from Sbaraglia and Dei Tos [2])

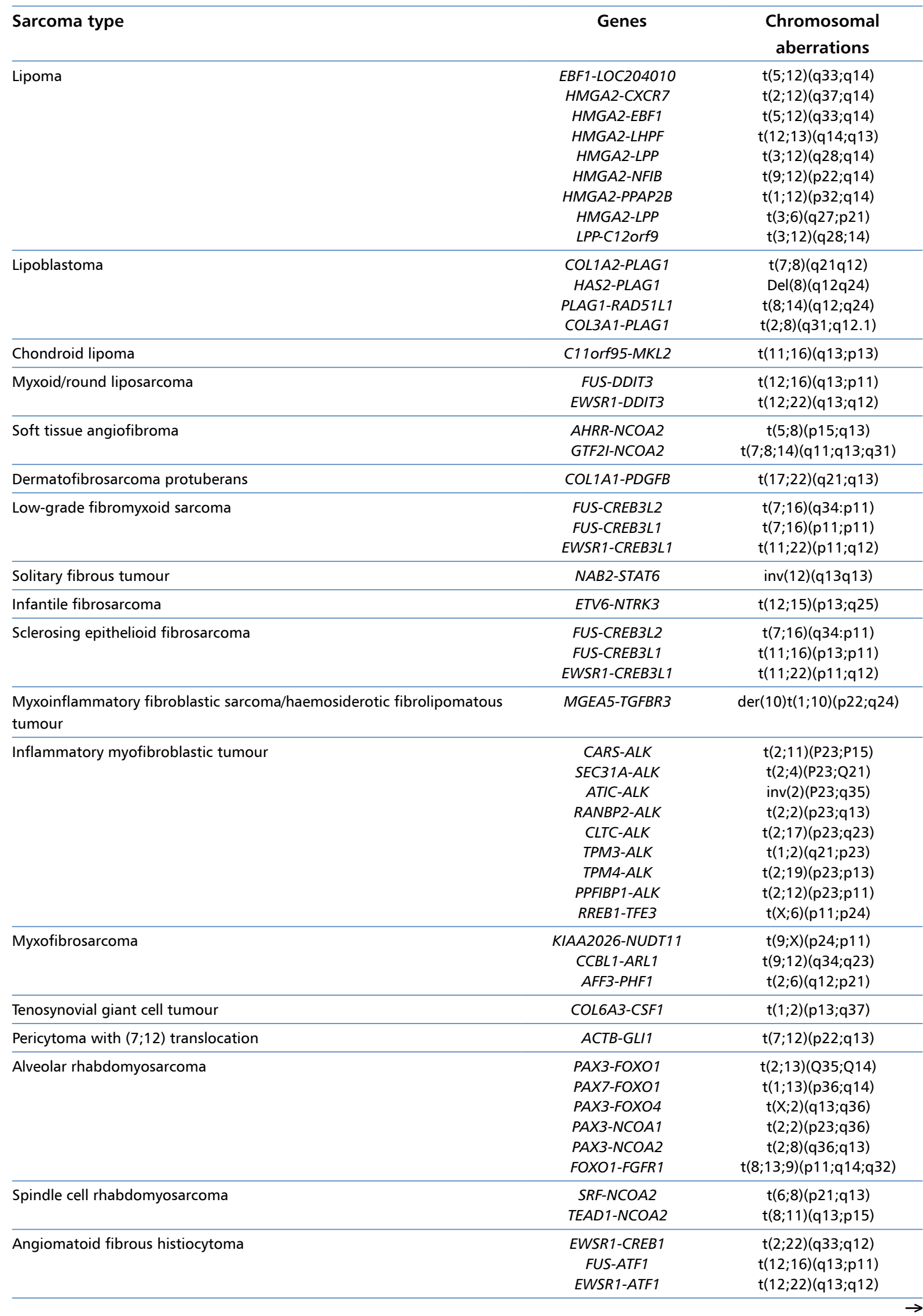


Table 1 (cont.). Genetic fusions in soft tissue sarcoma (modified, reprinted with permission from Sbaraglia and Dei Tos [2])

\begin{tabular}{|c|c|c|}
\hline Sarcoma type & Genes & $\begin{array}{c}\text { Chromosomal } \\
\text { aberrations }\end{array}$ \\
\hline \multirow[t]{3}{*}{ Ossifying fibromyxoid tumour } & EP400-PHF1 & $t(6 ; 12)(p 21 ; q 24)$ \\
\hline & MEAF6-PHF1 & $t(1 ; 6)(p 34 ; p 21)$ \\
\hline & ZCЗH7B-BCOR & $t(X ; 22)(p 11 ; q 13)$ \\
\hline \multirow[t]{9}{*}{ Myoepithelioma/mixed tumour } & EWSR1-ATF1 & $t(12 ; 22)(Q 13 ; q 12)$ \\
\hline & EWSR1-PBX1 & $t(1 ; 22)(q 23 ; q 12)$ \\
\hline & EWSR1-POU5F1 & $t(6 ; 22)(p 21 ; q 12)$ \\
\hline & EWSR1-ZNF444 & $\mathrm{t}(19 ; 22)(\mathrm{q} 13 ;, q 12)$ \\
\hline & EWSR1-KLF17 & $t(1 ; 22)(p 34.1 ; q 12)$ \\
\hline & EWSR1-PBX3 & $\mathrm{t}(9 ; 22)(q 12.2 ; q 33.3)$ \\
\hline & FUS-KLF17 & $\mathrm{t}(1 ; 16)(\mathrm{p} 34.1 ; \mathrm{p} 11)$ \\
\hline & LIFR-PLAG1 & $t(5 ; 8)(p 13 ; q 12)$ \\
\hline & $S R F-E 2 F 1$ & $\mathrm{t}(20 ; 6)(\mathrm{q} 11 ; \mathrm{p} 21)$ \\
\hline \multirow[t]{3}{*}{ Clear cell sarcoma } & EWSR1-ATF1 & $\mathrm{t}(12 ; 22)(q 13 ; q 12)$ \\
\hline & EWSR1-CREB1 & $t(2 ; 22)(q 33 ; q 12)$ \\
\hline & IRX2-TERT & $\operatorname{del}(5)(p 15.33)$ \\
\hline \multirow[t]{4}{*}{ Synovial sarcoma } & SS18-SSX1 & $t(X ; 18)(p 11 ; q 11)$ \\
\hline & SS18-SSX2 & $t(X ; 18)(p 11 ; q 11)$ \\
\hline & SS18-SSX4 & $t(X ; 18)(p 11 ; q 11)$ \\
\hline & SS18L1-SSX1 & $t(X ; 20)(p 11 ; q 13)$ \\
\hline \multirow[t]{3}{*}{ Biphenotypic sinonasal sarcoma } & PAX3-MAML3 & $t(2 ; 4)(q 35 ; q 31.1)$ \\
\hline & PAX3-NCOA1 & $\mathrm{t}(2 ; 2)(q 35 ; p .23)$ \\
\hline & PAX3-FOXO1 & $t(2 ; 13)(q 35 ; q 14)$ \\
\hline Alveolar soft part sarcoma & ASPSCR1-TFE3 & $t(X ; 17)(p 11 ; q 25)$ \\
\hline \multirow[t]{5}{*}{ Extraskeletal myxoid chondrosarcoma } & EWSR1-NR4A3 & $t(9 ; 22)(q 31 ; q 12)$ \\
\hline & TAF15-NR4A3 & $\mathrm{t}(9 ; 17)(\mathrm{q} 31 ; q 12)$ \\
\hline & TFG-NR4A3 & $t(9 ; 3)(q 31 ; q 12)$ \\
\hline & TCF12-NR4A3 & $t(9 ; 15)(q 31 ; q 21)$ \\
\hline & HSPA8-NR4A3 & $t(9 ; 11)(q 31 ; q 24)$ \\
\hline Desmoplastic small round cell tumour & EWSR1-WT1 & $t(11 ; 22)(p 13 ; q 12)$ \\
\hline \multirow[t]{16}{*}{ Ewing sarcoma and Ewing-like sarcomas } & EWSR1-FLI1 & $\mathrm{t}(11 ; 22)(\mathrm{q} 24 ; \mathrm{q} 12)$ \\
\hline & EWSR1-ERG & $\mathrm{t}(21 ; 22)(q 22 ; q 12)$ \\
\hline & FUS-ERG & $\operatorname{der}(21) t(16 ; 21)$ \\
\hline & EWSR1-ETV1 & $t(7 ; 22)(p 21 ; q 12)$ \\
\hline & EWSR1-ETV4 & $\mathrm{t}(17 ; 22)(q 21 ; q 12)$ \\
\hline & EWSR1-FEV & $\mathrm{t}(2 ; 22)(\mathrm{q} 35 ; \mathrm{q} 12)$ \\
\hline & EWSR1-NFATC2 & $\mathrm{t}(20 ; 22)(q 13 ; q 12)$ \\
\hline & EWSR1-PATZ1 & $\operatorname{inv}(22)(q 12 q 12)$ \\
\hline & EWSR1-SMARCA5 & $\mathrm{t}(4 ; 22)(\mathrm{q} 31 ; q 12)$ \\
\hline & EWSR1-POU5F1 & $t(6 ; 22)(p 21 ; q 12)$ \\
\hline & EWSR1-SP3 & $t(2 ; 22)(q 31 ; q 12)$ \\
\hline & FUS-FEV & $\mathrm{t}(2 ; 16)(\mathrm{q} 35 ; \mathrm{p} 11)$ \\
\hline & $C I C-D U X 4$ & $t(4 ; 19)(q 35 ; q 13)$ \\
\hline & CIC-FOXO4 & $t(X ; 19)(q 13 ; q 13)$ \\
\hline & BCOR-CCNB3 & $\operatorname{inv}(X)(p 11.4 p 11.22)$ \\
\hline & FUS-NCATC2 & $t(16 ; 20)(p 11 ; q 13)$ \\
\hline Perivascular epithelioid cell tumours & SFPQ-TFE3 & $t(X ; 1)(p 11 ; p 34)$ \\
\hline Soft tissue chondroma & $H M G A 2-L P P$ & $t(3 ; 12)(q 28 ; 214)$ \\
\hline \multirow[t]{2}{*}{ Mesenchymal chondrosarcoma } & HEY1-NCOA2 & $\operatorname{del}(8)(q 13 ; q 21)$ \\
\hline & IRFBP2-CDX1 & $t(1 ; 5)(q 42 ; q 32)$ \\
\hline Epithelioid haemangioma & ZFP36-FOSB & $\mathrm{t}(19 ; 19)(\mathrm{q} 13.32 ; \mathrm{q} 13.2)$ \\
\hline \multirow[t]{2}{*}{ Epithelioid haemangioendothelioma } & WWTR1-CAMTA1 & $t(1 ; 3)(p 36 ; q 25)$ \\
\hline & YAP1-TFE3 & $t(x ; 11)(p 11 ; q 22)$ \\
\hline Pseudomyogenic (epithelioid sarcoma-like) haemangioendothelioma & SERPINE1-FOSB & $t(7 ; 19)(q 22 ; q 13)$ \\
\hline Angiosarcoma & CIC-LEUTX & $\mathrm{t}(19 ; 19)(\mathrm{q} 13.11 ; \mathrm{q} 13.2)$ \\
\hline
\end{tabular}


and their development can be driven by changes in the Hippo pathway [8].

\section{Liposarcoma}

Liposarcomas are divided into several subgroups that differ in clinical course and molecular perturbations. At present, liposarcomas are classified as well-differentiated, dedifferentiated, diversified, mucoid, round cell, and multiform.

\section{Well-differentiated/atypical liposarcoma (WDLS)}

Approximately $80 \%$ of atypical liposarcomas are characterised by the presence of additional ring or giant marker chromosomes that contain amplified material in the region 12q13-15. This fragment can have variable length and contains genes like MDM2, TSPAN31, CDK4, HMGA2, CPM, and FRS2 [9]. The MDM2 and $\mathrm{CDK} 4$ proteins are involved in cell cycle regulation - MDM2 by binding to the p53 protein and inhibiting its function and CDK4 by stimulating the phosphorylation of the RB protein [9].

The 1q21-22 region including COAS and PRUNE oncogenes is also often amplified [10]. PRUNE is a negative regulator of the $\mathrm{nm} 23-\mathrm{H} 1$ metastasis suppressor protein, and its amplification leads to a decrease in the level of free nm23-H1 and subsequently increased proliferation and migration of cells [11]. Moreover, in some cases of WDLS co-amplifications of 12q21-22 were also observed [12].

\section{Dedifferentiated liposarcoma (DDLS)}

Dedifferentiated liposarcoma is considered to be a more aggressive form derived from well-differentiated liposarcoma, and it is similarly characterised by the presence of additional giant marker and ring chromosomes. DDLS is characterised by more copy number alterations (CNAs) than WDLS $-21 \%$ and $5.7 \%$, respectively [13]. Among the numerous chromosome disorders, the most common is amplification of the 12q13-1 region containing the MDM2 gene and a few rarer co-amplifications, among others $1 \mathrm{q} 32$ and $6 \mathrm{q} 23$, within which the $J U N$ and $A S K 1$ genes are located [9, 14]. In the majority of cases where $M D M 2$ amplification is found, p53 gene mutations are absent, which distinguishes dedifferentiated liposarcoma from other high-grade sarcomas [15]. It is also believed that activation of JUN signalling pathway may be involved in the progression of WDLS to DDLS [16].

An important mechanism involved in the dedifferentiation of WDLS into DDLS is the inhibition or complete blocking of adipogenesis in which LIPE, PLIN, and PLIN2 genes are involved [17]. The expression level of genes associated with apoptosis $(B A X, B I R C 5$, $S U L F 1)$, cytoskeletal function (CTNNB 1, MARKS, TMP4, PLEC), Ras signalling pathway (RAB23, $H R A S L S 3, R A B 20)$, transcription factors (TLE4, $F O X F 2$, SOX11), and cell cycle control (MAPK1, $C D C 2, C C N B 2)$ differs significantly between DLLS and WDLS and may be involved in the dedifferentiation process [18].

\section{Myxoid and round cell liposarcoma}

The main chromosomal aberration in myxoid and round cell liposarcoma is $\mathrm{t}(12 ; 16)(\mathrm{q} 13 ; \mathrm{p} 11)$ translocation, which occurs in over $90 \%$ of cases $[14,19]$. This translocation leads to fusion of CHOP (DDIT3) and TLS (FUS) genes located on chromosomes 12 and 16 , respectively [20]. The presence of $T L S-C H O P$ is a highly specific marker, not present in other subtypes of myxoid sarcomas [14]. The CHOP gene encodes a nuclear protein belonging to the $\mathrm{C} / \mathrm{EBP}$ transcription factor family and is involved in the differentiation of adipocytes, erythropoiesis, and neoplastic transformation. The $T L S$ gene encodes a nuclear RNA-binding protein that reacts with serine-arginine proteins involved in RNA splicing [14]. During the translocation, a joining of $T L S$ gene transcription activating domain with the leucine zipper domain $C H O P$ occurs. The resulting fusion protein leads to a change in the level of transcription of many genes, adipogenesis inhibition, and stimulation of cell proliferation resulting in tumour formation [21]. Due to the high homology of $T L S$ and EWS genes, in rare cases (5-10\%) a t(12; 22)(q13; q12) translocation is revealed, leading to CHOP and EWS gene fusions [22]. TLS-CHOP and EWS-CHOP translocations can be detected not only on the chromosomal level by FISH, but also at the transcript level using RT-PCR. To date, 11 variants of TLS-CHOP transcripts have been identified, the most common of which are type 2 (exon $5 T L S$ and $2 C H O P$, approximately $66 \%$ ), type 1 (exon $7 T L S$ and $2 C H O P$ ), and type 3 (exon $8 T L S$ and 2 CHOP) [14, 23]. Furthermore, fusion mRNA can also be detected in the blood [24].

Apart from the specific gene fusions in $14-18 \%$ of MLPS cases activating mutation in PIK3CA gene or homozygous loss of PTEN gene are observed (the product of the latter is an inhibitor of the PIK3CA pathway). They lead to the activation of the PI3K/AKT signalling pathway and to excessive proliferation and increased cell invasiveness. A similar effect is observed in the case of overexpression of insulin-like growth factor type 2 (IGF2) and type 1 receptor (IGFR1) [25]. Telomerase reactivation observed in $39 \%$ of cases also contributes to MLS pathogenesis [26]. 


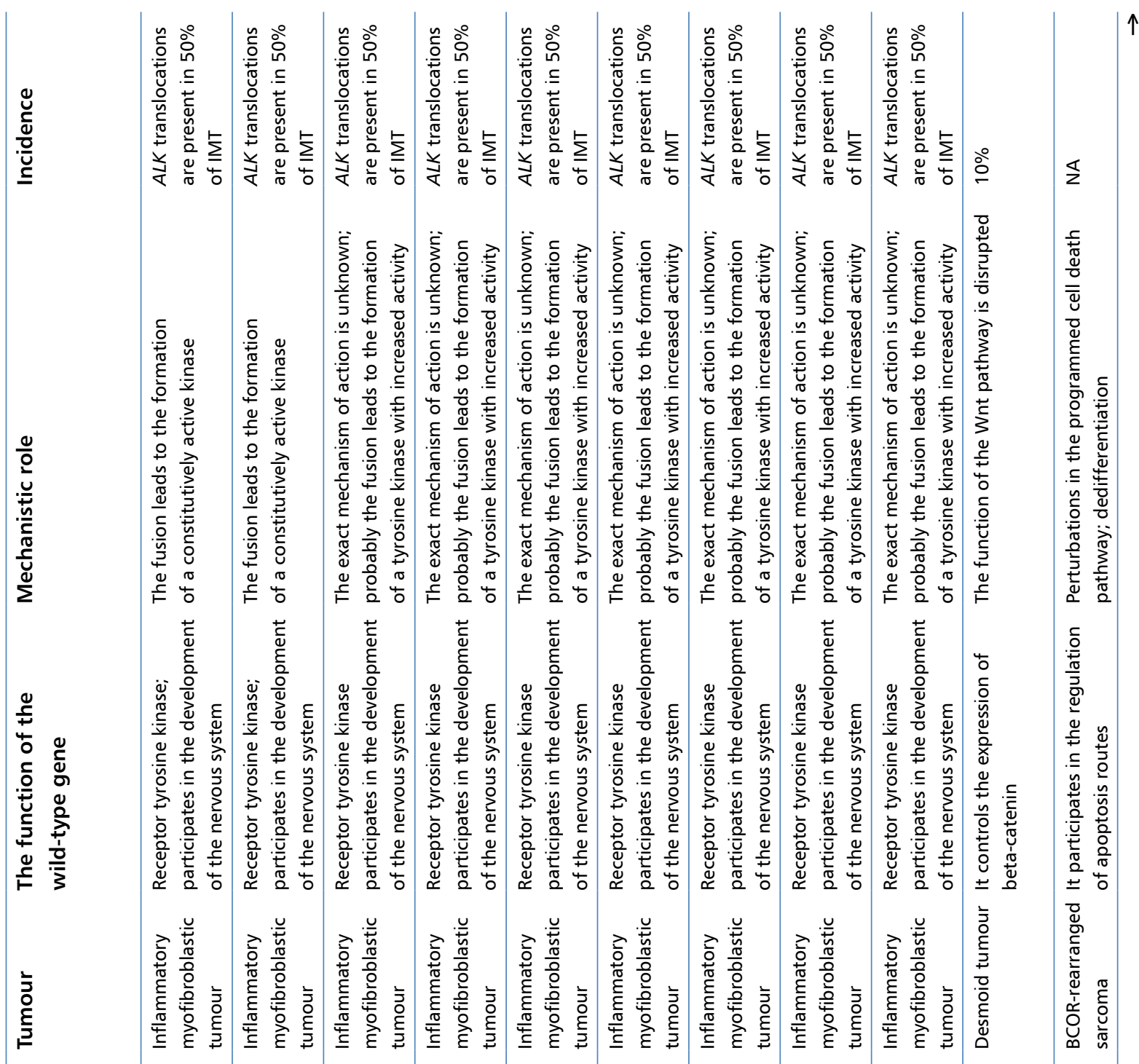

\begin{tabular}{|c|c|c|c|c|c|c|c|c|c|c|c|}
\hline 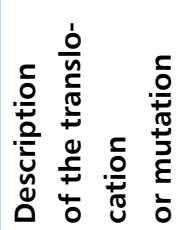 & 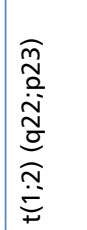 & 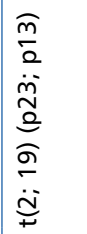 & 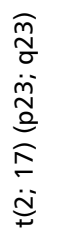 & 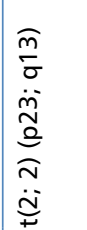 & 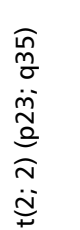 & 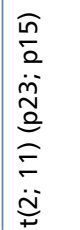 & 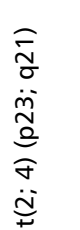 & 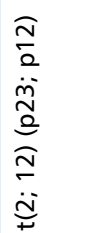 & n. & 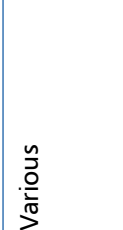 & $\begin{array}{l}\bar{a} \\
\frac{2}{2} \\
\frac{2}{2} \\
\frac{x}{3} \\
\underline{3}\end{array}$ \\
\hline 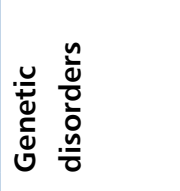 & 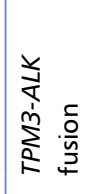 & 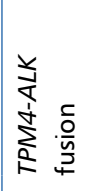 & 紊 & 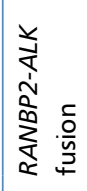 & co & 希 & 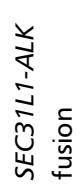 & 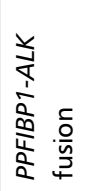 & $\begin{array}{ll}\frac{1}{1} \\
\frac{1}{1} \\
\frac{1}{0} \\
\frac{0}{00} \\
\frac{0}{02} \\
\frac{0}{2}\end{array}$ & 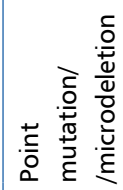 & 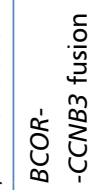 \\
\hline 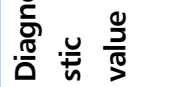 & $\stackrel{\check{\nu}}{\nu}$ & $\stackrel{\check{\nu}}{\succ}$ & 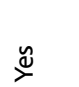 & 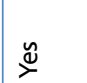 & $\stackrel{\breve{y}}{\nu}$ & $\stackrel{\breve{y}}{\succ}$ & $\stackrel{\breve{\nu}}{\nu}$ & 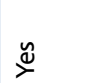 & $\stackrel{\breve{y}}{\nu}$ & $\stackrel{\breve{y}}{\succ}$ & $\stackrel{\breve{\nu}}{\nu}$ \\
\hline 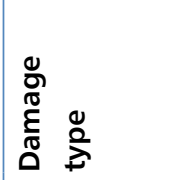 & 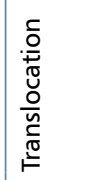 & 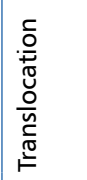 & 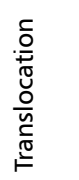 & 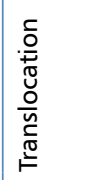 & 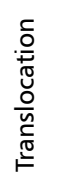 & 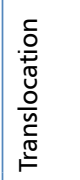 & 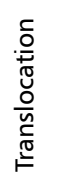 & 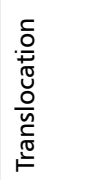 & 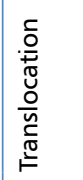 & 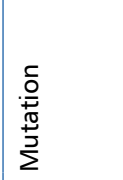 & 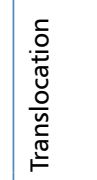 \\
\hline & 过 & $\mid \frac{z}{4}$ & $\frac{3}{4}$ & $\stackrel{\square}{~}$ & $\frac{3}{4}$ & 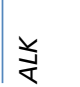 & 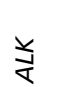 & 光 & $\stackrel{\square}{4}$ & $\frac{1}{4}$ & ర్ర్ల్ \\
\hline
\end{tabular}




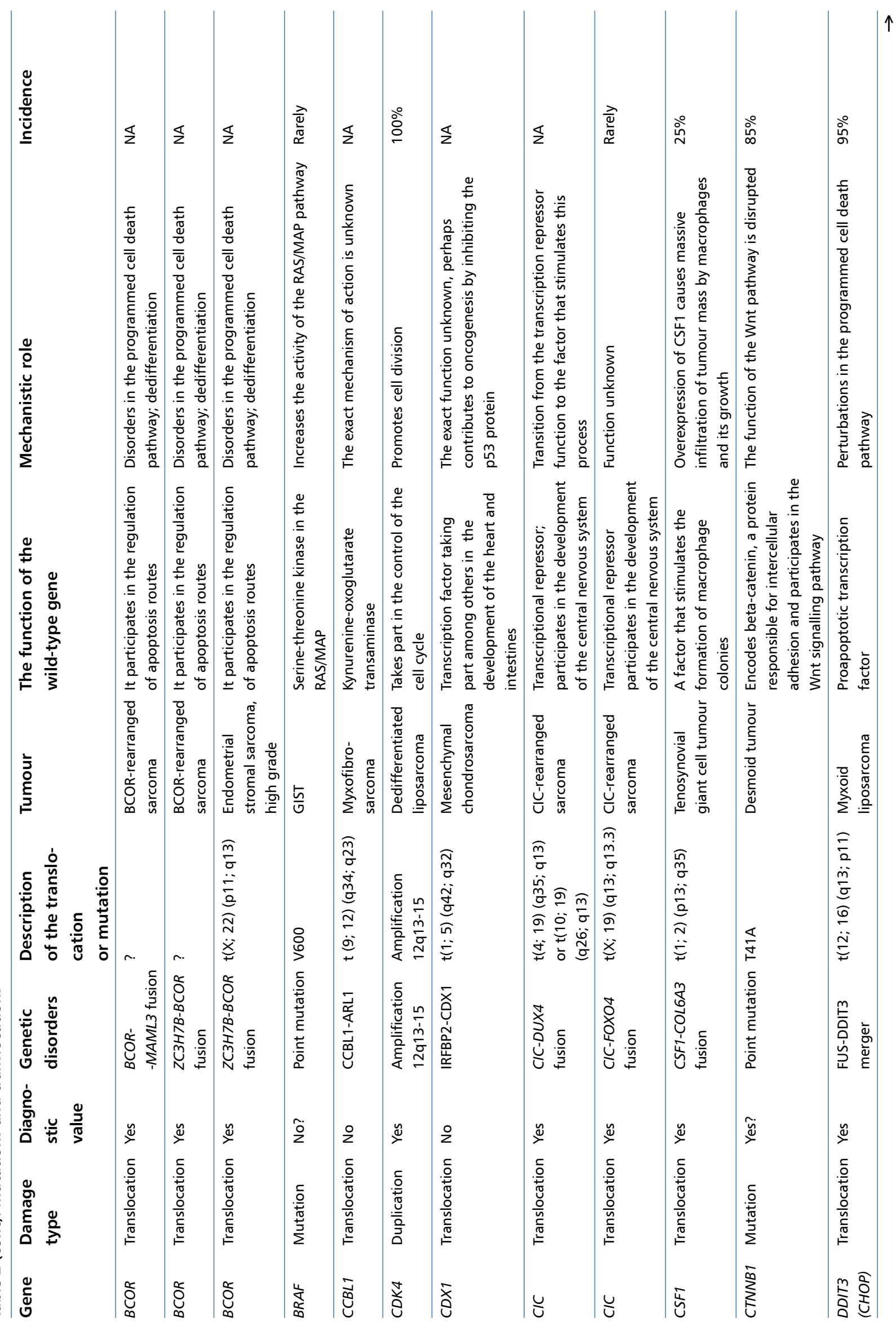




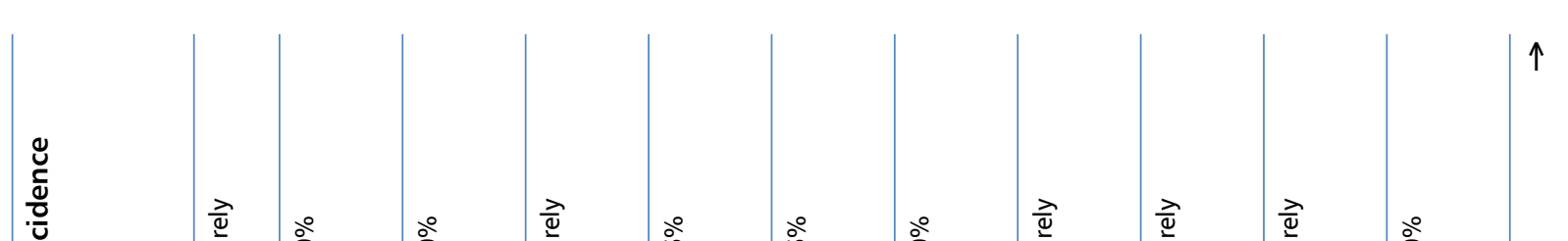

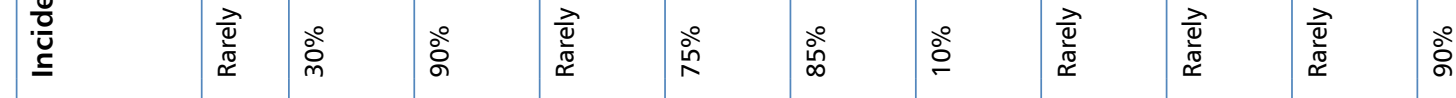

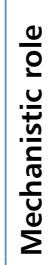
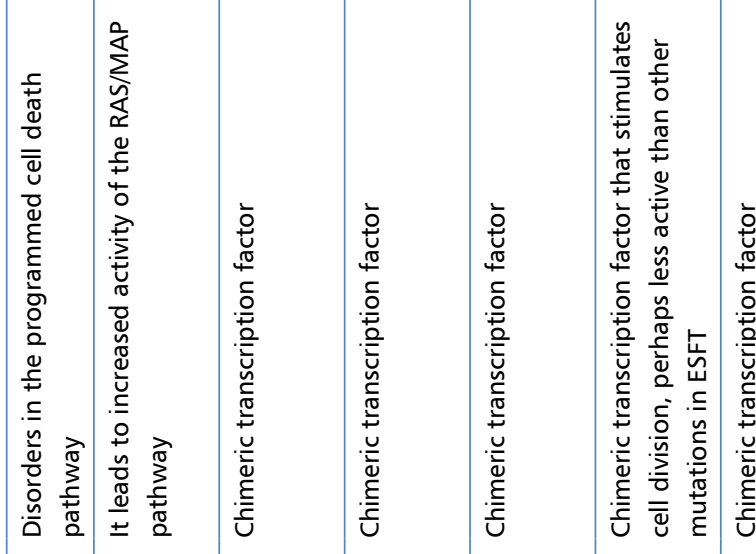

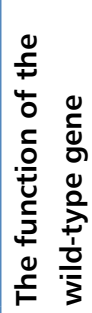

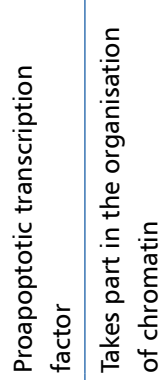

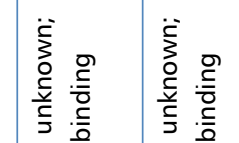

ड़ $\overline{\bar{y}}$ है

言,

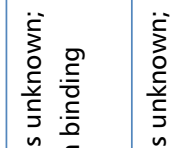

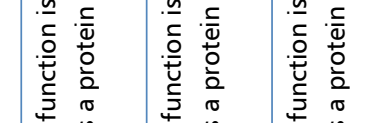

政

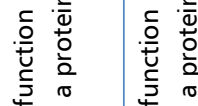

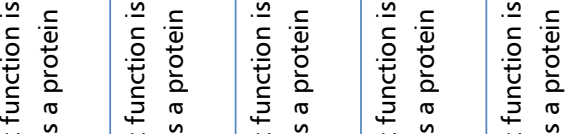

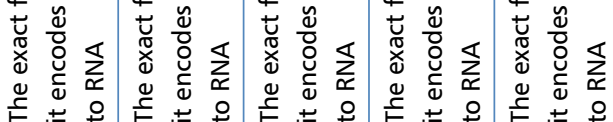
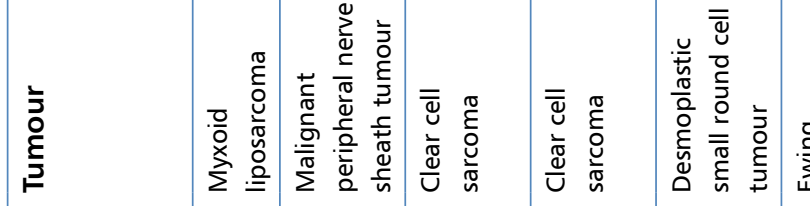

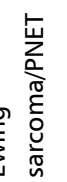

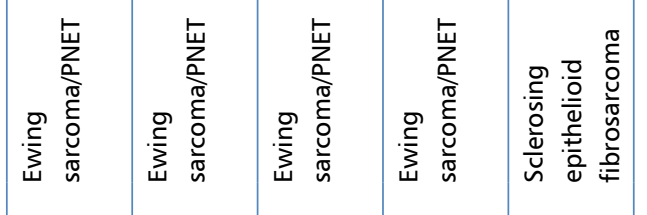

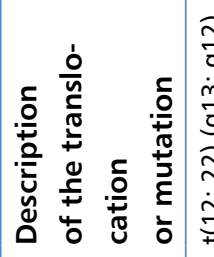

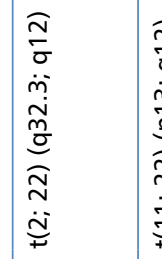

In

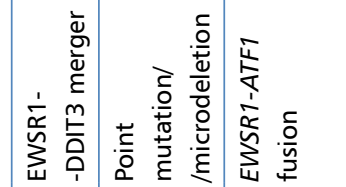

离

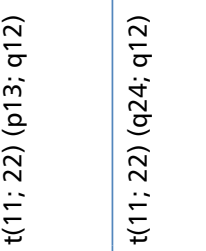

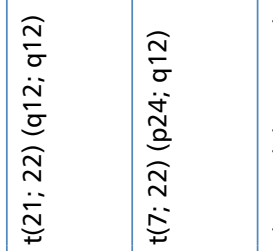

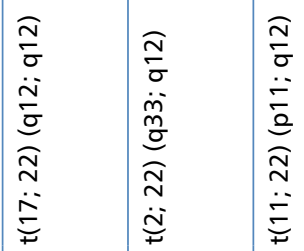

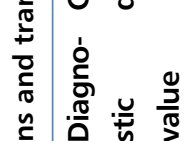

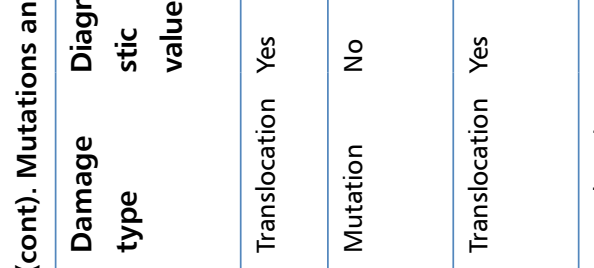

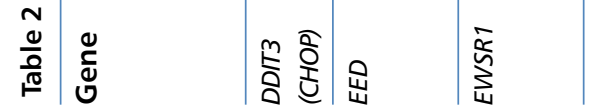

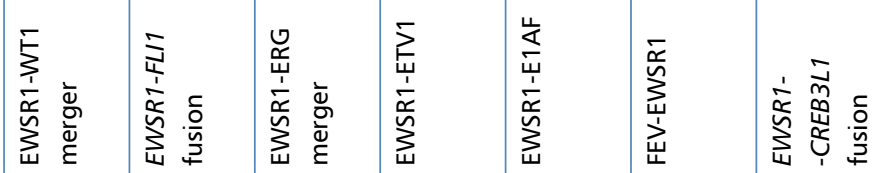




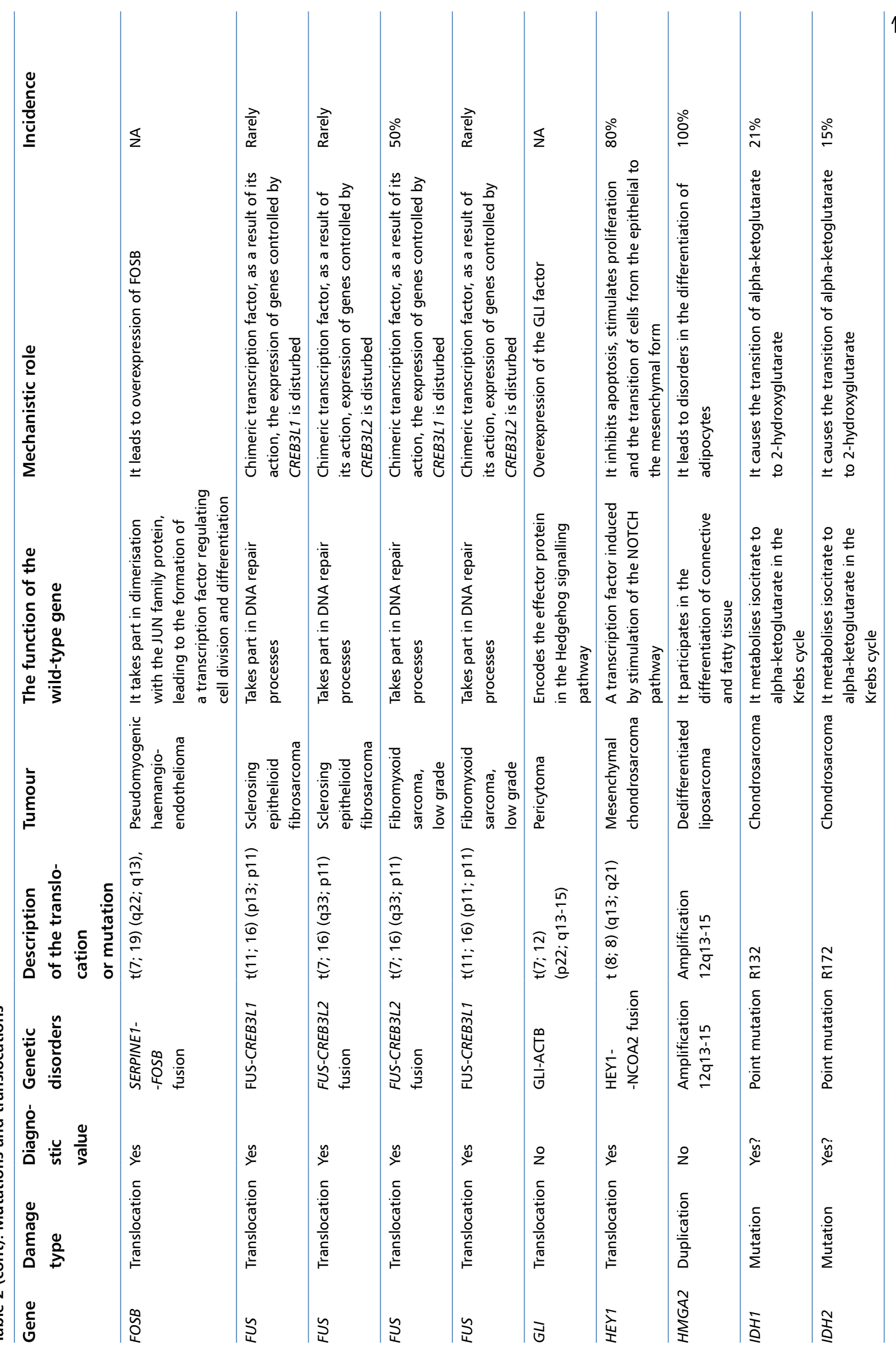




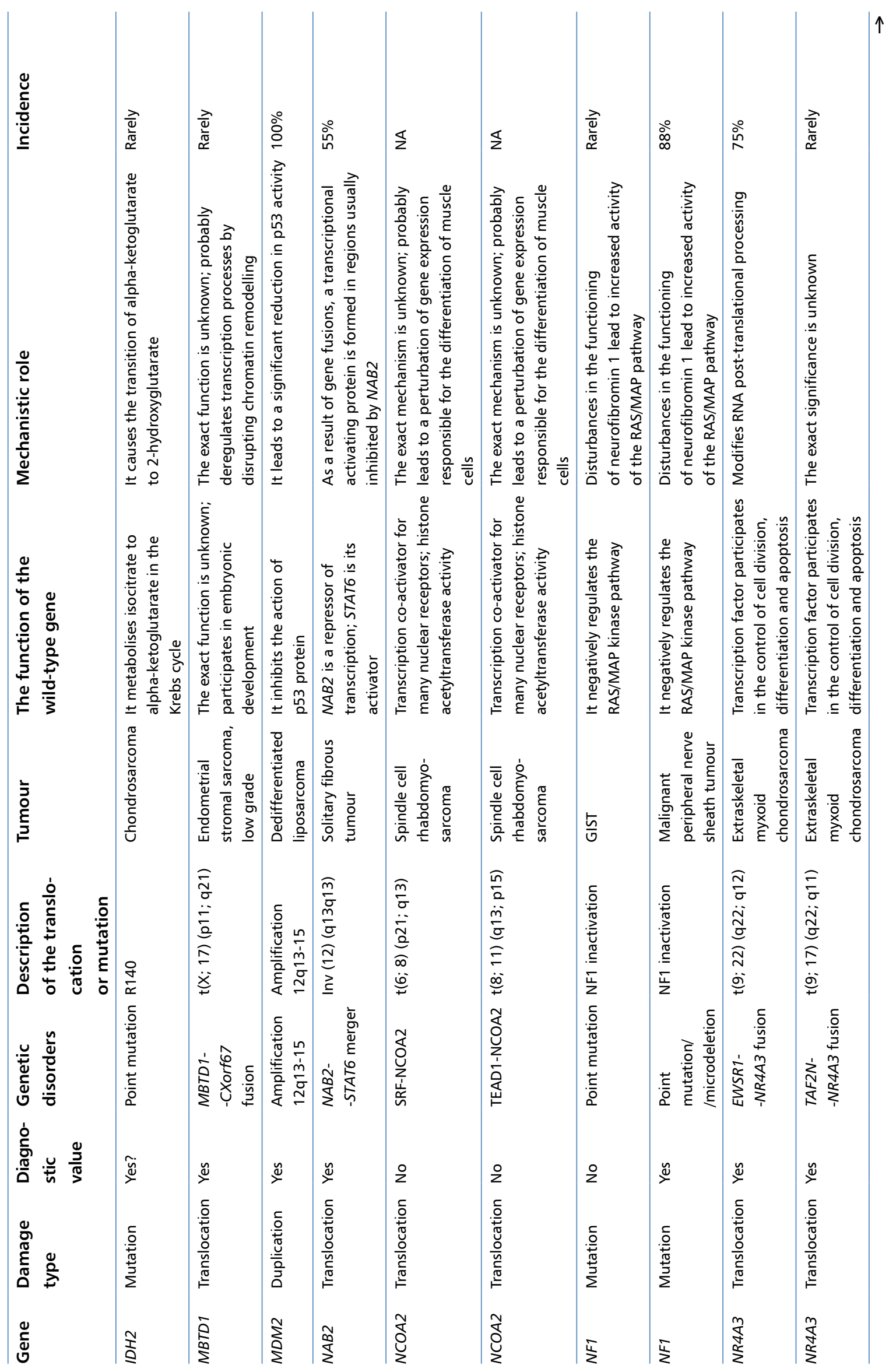



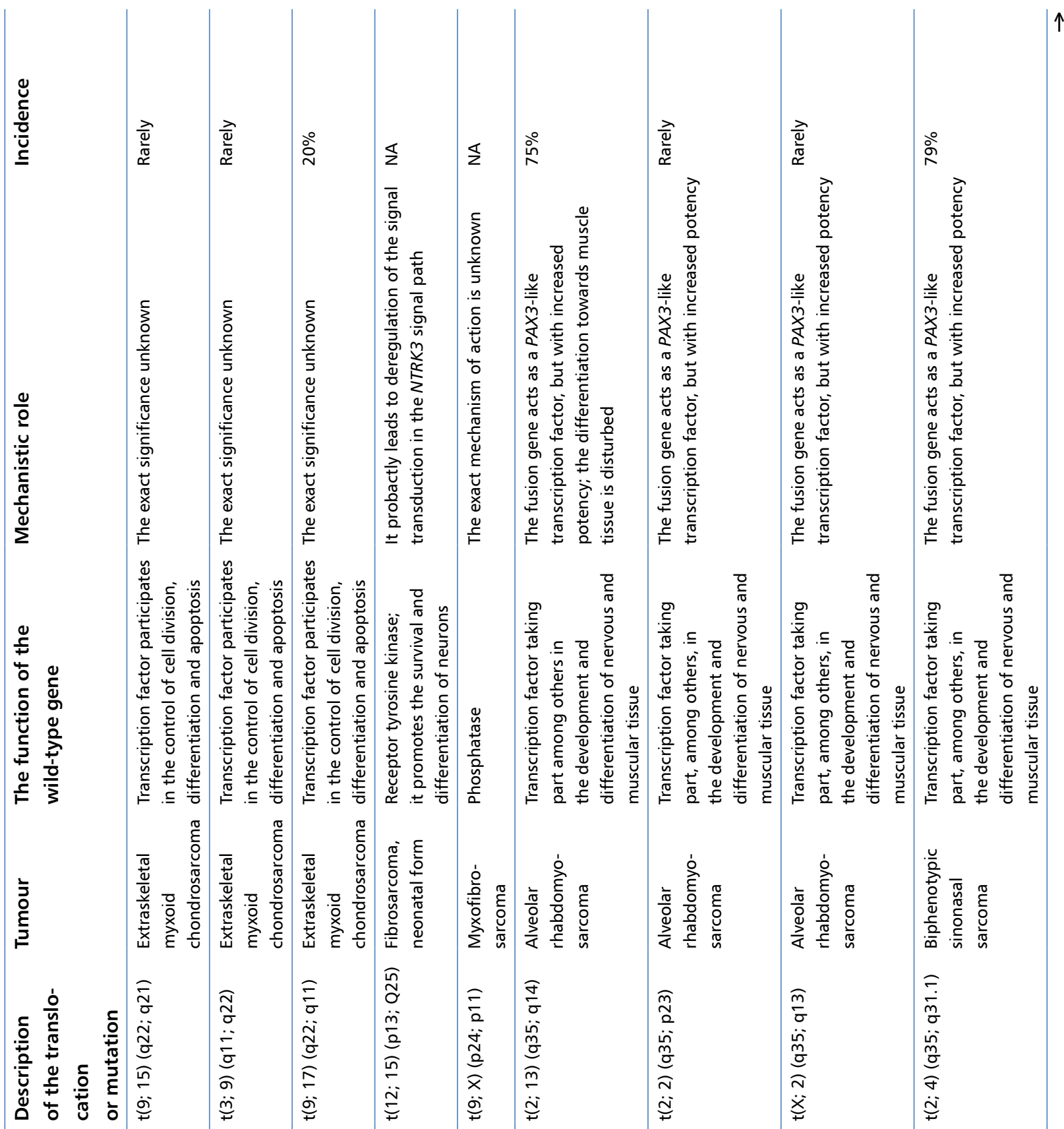

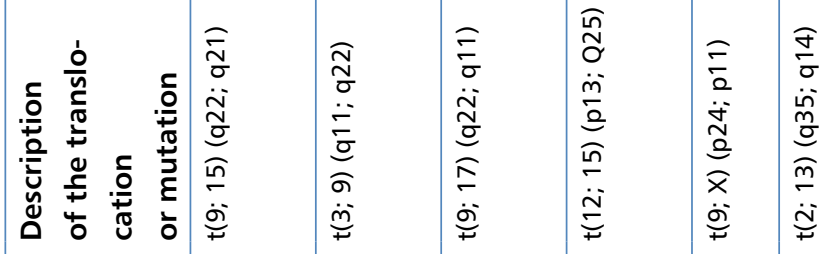

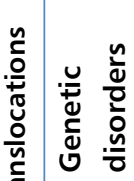

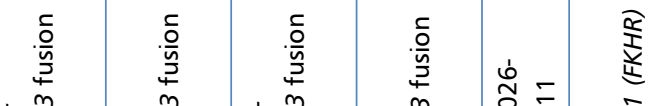

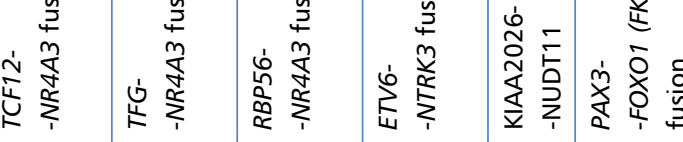
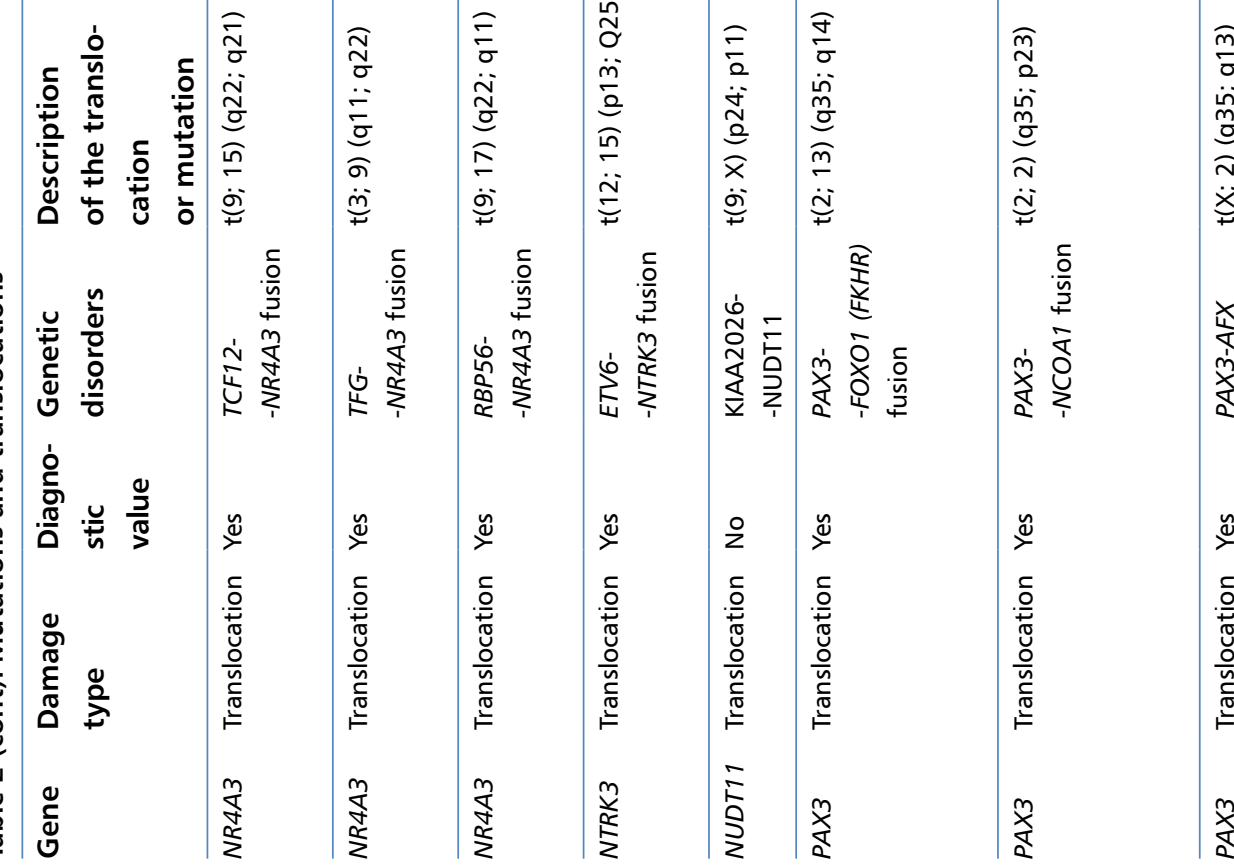

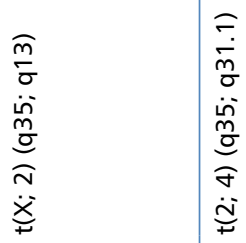
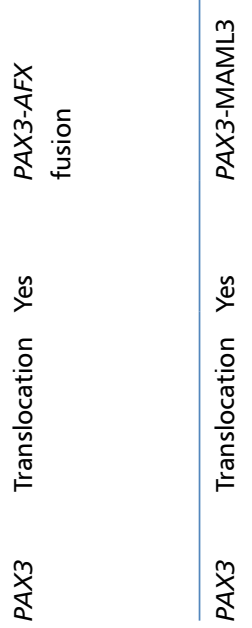


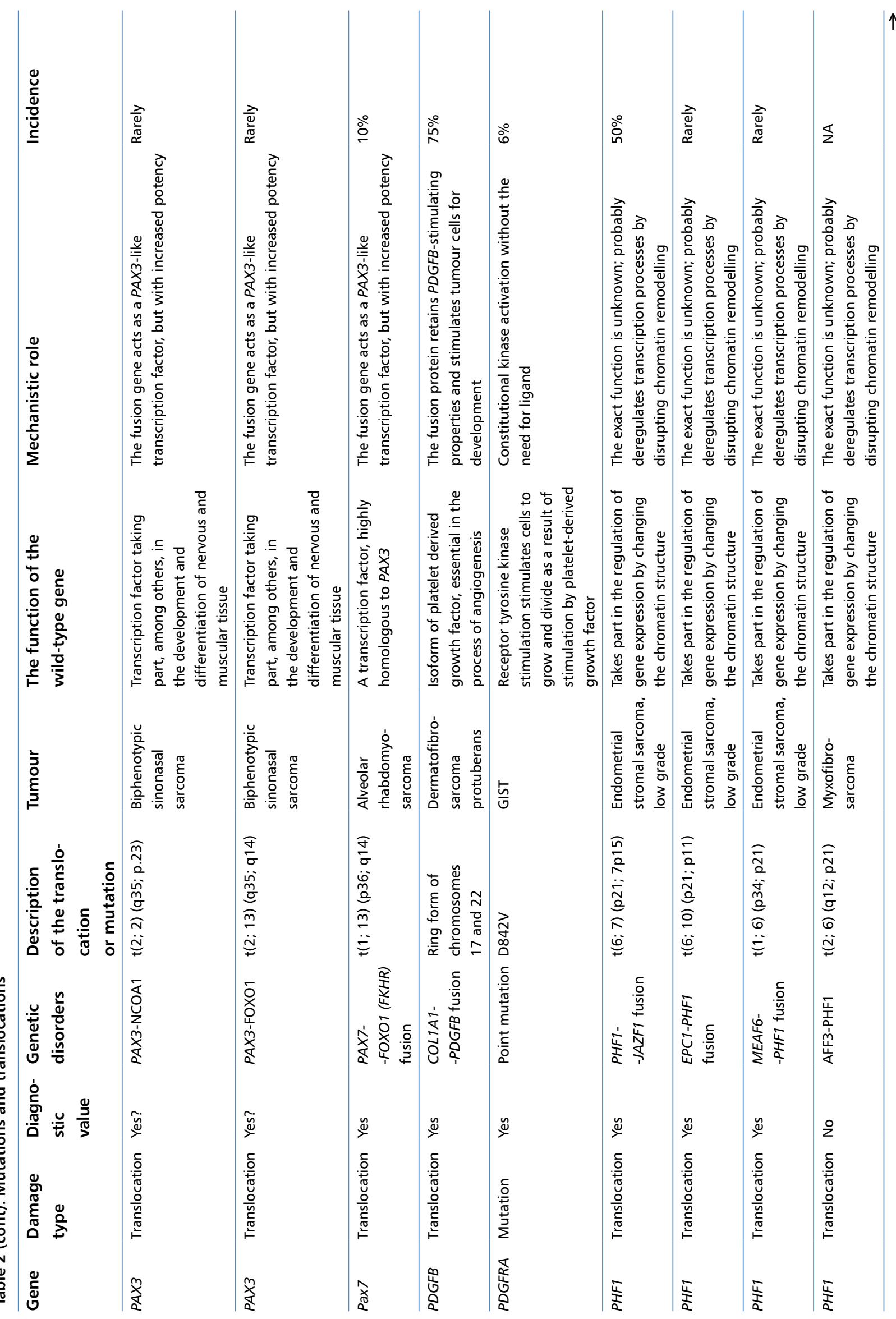



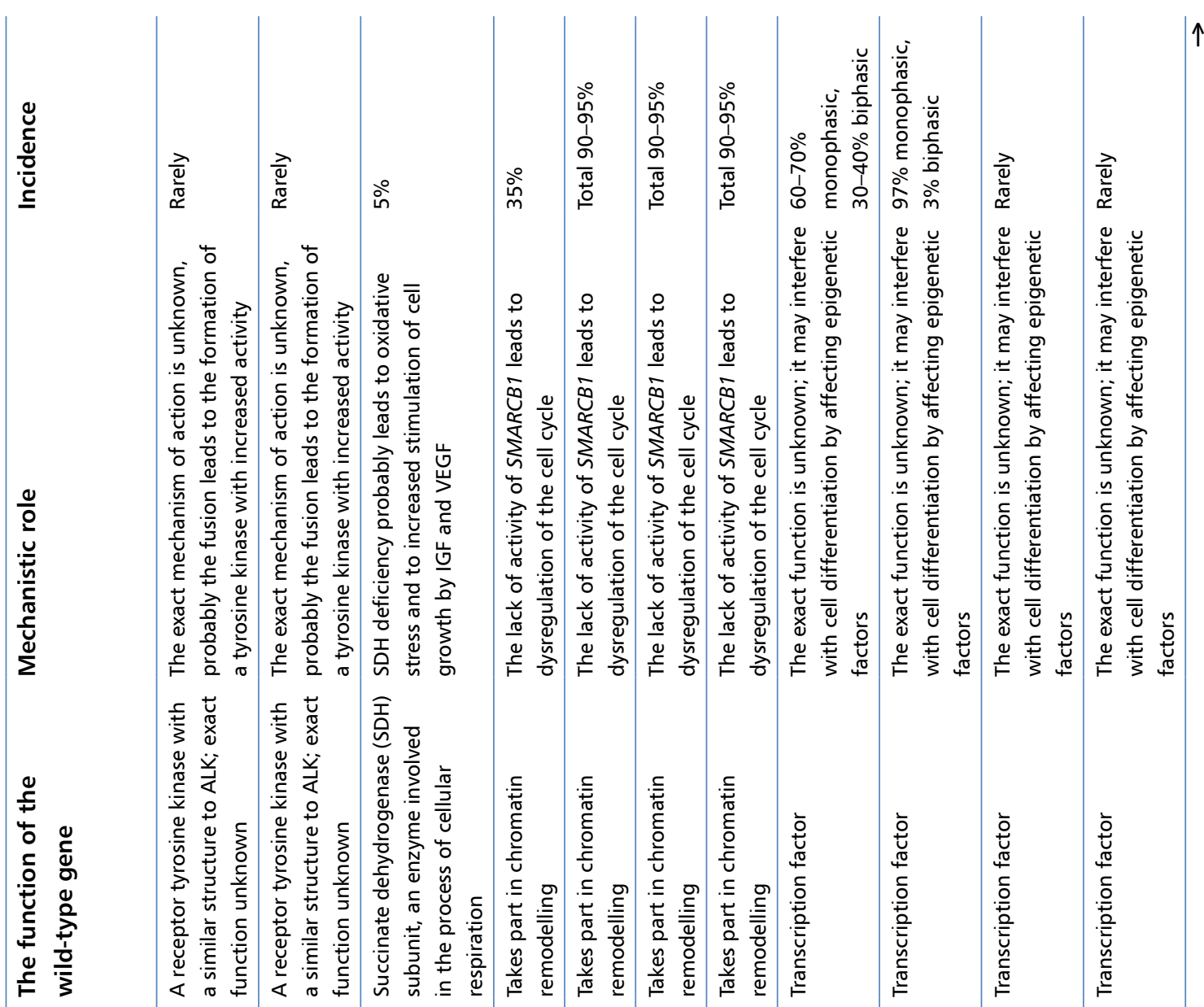

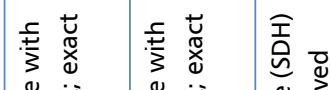

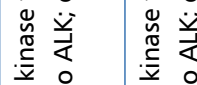

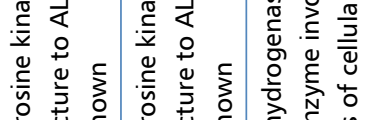

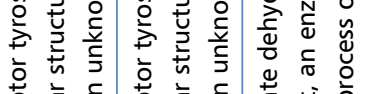

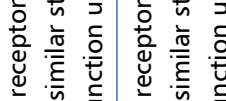

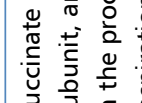

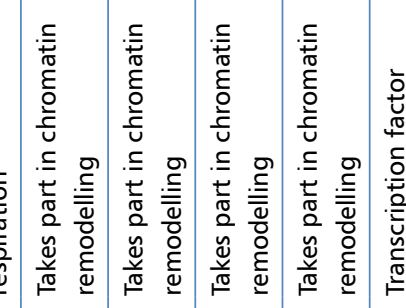

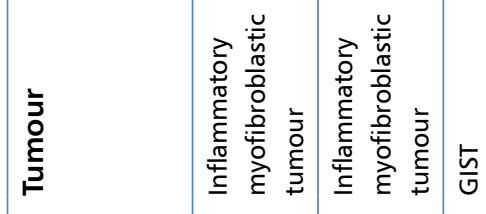

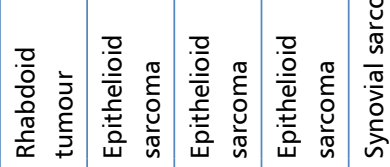

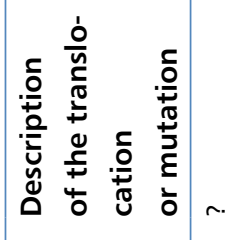

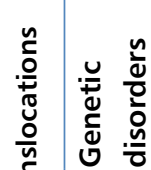

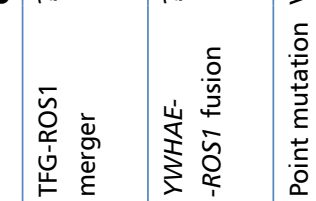

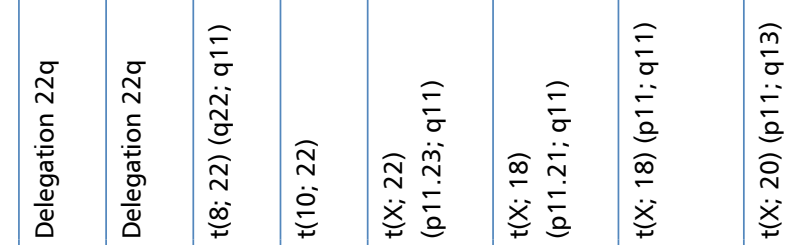

要离

气ั

$\stackrel{+}{\stackrel{5}{5}}$

咅

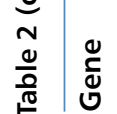

I E

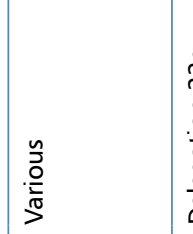

$\stackrel{\frac{0}{0}}{\frac{0}{0}}$

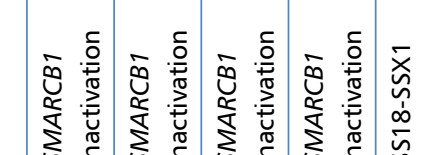

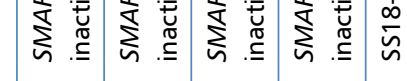

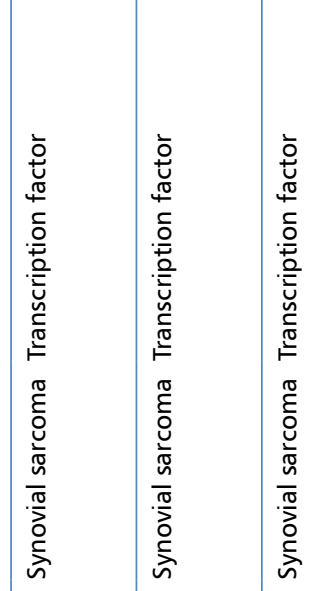




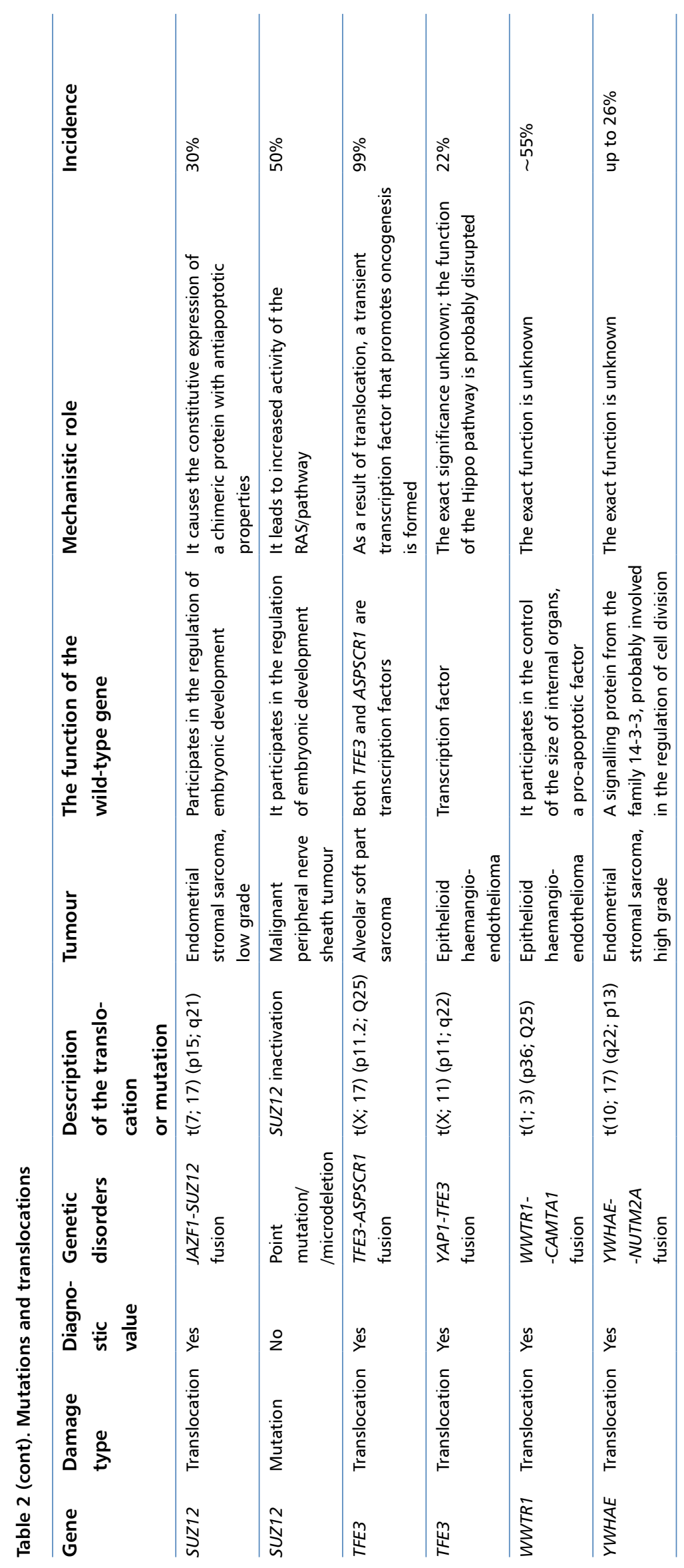




\section{Pleomorphic liposarcoma (PLS)}

The cytogenetic picture of pleomorphic liposarcoma is associated with the occurrence of aneuploidy with numerous chromosomal aberrations. The number of chromosomes in the cell may exceed 200, and within the tumour there may be a large heterogeneity of cells, which significantly hinders the identification of characteristic rearrangements [9]. Numerous amplifications are observed in the genetic profile, including $1 \mathrm{p} 21$, 1q21-22, 5p13-15, 7q22, 13q31-32, and 20q13. Mutations loss of function in TP53 and NF1 genes have also been described. CCND1, CCND2, MYB, MDM2, GLI1, and $C D K 4$ gene amplifications are present in PLS [27].

\section{Leiomyosarcoma}

Leiomyosarcomas are characterised by complex genetic perturbations and highly complex karyotypes with numerous losses and amplifications of multiple chromosomal regions. Available data are very complex and limited. Genomic hybridisation assays revealed that genetic perturbations in leiomyosarcomas encompass 2218 genes in 25 chromosomal regions [28]. The most common are losses within 10q, 13q14-21, and 19p regions [29-31]. Amplifications are most commonly found within $17 \mathrm{p}$ and also 5p15, 8q24, 15q25-26, and Xp [29]. It should be noted that the number of cytogenetic abnormalities increases with the size of the tumour [29], and this correlates negatively with the patients' survival [32].

Despite the fact that the $17 \mathrm{p}$ region in which the TP53 gene is located is amplified, one of the main mechanisms underlying the development of leiomyosarcomas is the loss of tumour suppressor functions of p53 and $\mathrm{Rb}$ proteins. 19p deletion and loss of function of $p 16 I N K$ and $A R F$ genes located there, which are important regulators of tumour suppressors RB and p53, are among the main mechanisms of inactivation of these genes [33]. The decrease of p16 expression may also result from methylation of $p 16 I N K 4$ gene promoter [34].

The second important mechanism involved in the development of leiomyosarcoma is direct loss of the $R B$ gene located in region 13q14.2-14.3 [31]. Moreover, in the amplified 17p11-12 region the COPS3 gene is located, whose activation leads to increased degradation of p53 protein in proteasomes. Thus, amplification of COPS3 is one of the mechanisms leading to inactivation of p53 [35]. In less common cases the loss of p53 protein function results from its inhibitor MDM2, which is overexpressed in more than $10 \%$ of leiomyosarcomas [36].

$\mathrm{PI} 3 \mathrm{~K} /$ Akt signalling pathway perturbations play an important role in pathogenesis, and they are overexpressed in many cases of leiomyosarcomas. The loss of the $10 \mathrm{q}$ region leads, among others, to the loss of the PTEN gene [29] - the negative regulator of this pathway [37]. Studies in animal models have shown that loss of PTEN function is an important, but insufficient element in the development of leiomyosarcoma [37]. It is believed that PTEN dysfunction also contributes to the development of genetic instability, and activation of the PI3K/Akt pathway increases the phosphorylation of $\mathrm{Mdm} 2$ protein and the loss of $\mathrm{p} 53$ protein function [38].

In the amplified $17 \mathrm{p} 11.2$ region the $M Y C O D$ gene is also located, which encodes a transcription factor specific for smooth muscle and cardiomyocytes, which regulates transcription of genes responsible for cell differentiation and migration [39]. The research indicates that perturbations of the DNA double-strand break repair mechanisms, resulting from the loss of $F A N C A$ and $B R C A 1$ gene function, are a potential mechanism involved in pathogenesis and a possible target of treatment with PARP inhibitors [38]. The genes potentially involved in the pathogenesis of leiomyosarcoma also include amplified $M Y C, M Y B, C O P S 3, G L I, C D K 4$, $S A S, F L F$, and PRUNE genes [40].

Based on recent studies, leiomyosarcomas have been divided into three classes based on overexpression of certain markers. Type I is characterised by overexpression of ACTG2, SLMAP, LMOD1, CFL2, and MYLK genes, type II by overexpression of $A R L 4 C, C D K 4$, CTNNB1, AURKA, RHEB, EGFR, CCND1, MTOR, $M A P K 1, N O T C H 2$, and ROR2 genes, and type III by overexpression of MDM4, ERB3, EPHA3, ESR1, and $E G F R$ genes and activation of pathways involved in metabolism, ion transport, and transcription regulation [41]. The role of individual pathways in the development of leiomyosarcoma requires deeper knowledge and further detailed research.

\section{Synovial sarcoma}

Synovial sarcoma (the name synovial is misleading because this tumour is not derived from synovial cells and does not express specific synovial markers; another name for this tumour is synovioma malignum) is a soft tissue tumour most commonly found in the lower limbs in young adults [42]. In the case of small tumours $(<5 \mathrm{~cm})$, the prognosis is favourable, larger tumours are associated with a higher risk of metastasis and local recurrence [43].

The specific chromosomal aberration in synovial sarcoma is $\mathrm{t}(\mathrm{X} ; 18)$ translocation, which is used for diagnostic purposes (using cytogenetic or RT-PCR methods) [44]. Synovial sarcoma is characterised by relatively small genetic complexity - almost half of primary tumours do not carry chromosomal aberrations other than $\mathrm{t}(\mathrm{X} ; 18)$, while in other cases only a small number of lesions occur [45]. Changes in the number of chromosomes and 
higher genetic complexity are more common in adults than in children [45]. Higher genetic complexity was observed in metastatic and recurrent tumours [46], it also correlated with a higher incidence of metastases and a shorter survival time [45].

Translocation $\mathrm{t}(\mathrm{X} ; 18)$ causes the fusion of SS18 gene (alternative name $S Y T$, chromosome 18) with genes from the $S S X$ family on X chromosome ( $S S X 1, S S X 2$, or less often $S S X 4)$. SS18 protein and proteins from the SSX family regulate transcription, although they are not transcription factors in the strict sense - they do not have DNA binding domains. SS18 stimulates the transcription, and SSX proteins inhibit this process. It seems that the SS18-SSX1 and SS18-SSX2 fusion effects are slightly different. $S S 18-S S X 1$ promotes proliferation, migration, and invasiveness of tumour cells, and SS18-SSX2 affects the adhesion and cytoskeleton of tumour cells [42].

In contrast to other malignancies, due to the relative chromosomal stability in synovial sarcoma, mutations within the TP53 gene are relatively rare. The unchanged p53 protein is found in the majority of synovial sarcomas, but its function can probably be altered, e.g. as a result of regulation by the AKT-PTEN pathway [47].

\section{Epithelioid sarcoma}

Epithelioid sarcoma is rare (less than $1 \%$ of all soft tissue sarcomas) and aggressive type of sarcoma occurring mainly in children and young adults. Although it is a tumour of mesenchymal origin, the cells have both mesenchymal and epithelial markers [48].

Epithelioid sarcoma can be divided into two subtypes: a distal (classic; most cases, lesions rather in the lower part of the body) and a proximal (lesions more in the upper body, including head and neck) with different histological characteristics. Distal epithelioid sarcoma is more common in younger patients (mean age of patients 29 years), with predominance in men. The proximal subtype is more common in older people (mean age of patients 40 years) [49].

In the vast majority of samples of this tumour, cells with very complex karyotype are observed, and only a small part of tumours have diploid or polyploid cells. Epithelioid sarcomas occurring in children have less complex karyotypes compared to malignancies found in adults. Translocations $(8 ; 22)(q 22 ; q 11)$ and $t(10 ; 22)$ were observed in distal and proximal epithelioid sarcoma, respectively. In most cases, the changes affect the longer arm of chromosome 22. Unlike other soft tissue sarcomas, epithelioid sarcoma cannot be distinguished by the unique cytogenetic pattern "characteristic" for this type of sarcoma [48].

Due to changes in the long arm of chromosome 22, a loss of $S M A R C B 1$ expression is observed in most cases of both types of epithelioid sarcomas [50]. Immunohistochemistry showed a loss of SMARCB1 expression in 85$93 \%$ of cases (depending on the source) [48]. Loss of expression occurs through various mechanisms, and a significant proportion may be gene silencing by miRNA, in particular by miR-765, an increased level of which appears to be specific for epithelioid sarcomas [51].

Gene SMARCB1 (another name INI1) (22q11) encodes the BAF47 protein (SWI/SNF-related matrix-associated, actin-dependent regulator of chromatin subfamily B member 1), which is one of the subunits of the ATP-dependent complex of SWI/SNF remodelling chromatin. The components of this complex are mutated in a significant number of tumours, in particular in the malignant rhabdoid tumour [52]. BAF47 acts as a tumour suppressor, and its inactivation leads to neoplastic transformation resulting from deregulation of target gene transcription [48].

In the case of epithelioid sarcoma, inactivation of $S M A R C B 1$ alone is not sufficient for neoplastic transformation. The $S M A R C B 1$ knock-out in a fibroblast cell line caused growth arrest and activated apoptosis mediated by p53 [53]. Only the coexistence of the SMARCB1 and TP53 mutations caused a dramatic increase in proliferation [54]. It is also postulated that other proteins and signalling pathways contribute to tumour progression due to the complex genetic landscape of epithelioid sarcoma [48].

\section{Ewing sarcoma}

According to the World Health Organisation classification, Ewing sarcoma is referred to as a malignant tumour with uncertain differentiation [2]. It accounts for $6-8 \%$ of primary malignant bone tumours. It is a rare malignancy, occuring most often in populations of European origin, with a frequency of 1.5 cases per million children, adolescents, and young adults [55]. Ewing sarcoma most often appears in the second decade of life, and there is a characteristic translocation causing EWSR1-ETS fusion [6]. In most cases they are translocations of EWS and genes from ETS transcription factor family, in over $85 \%$ of cases with FLII, in $10 \%$ with ERG [17]. The most frequent translocation is $\mathrm{t}(11 ; 22)(\mathrm{q} 24 ; \mathrm{q} 12)$. The EWSR 1 gene is located at $22 \mathrm{q} 12$ and $F L I 1$ at $11 \mathrm{q} 24$. There are several variants of these translocations. Expression of the fusion protein in normal cells leads to their death, while in an undifferentiated or malignant cells it causes disorders of differentiation resulting in the development of malignancy $[56,57]$. The effect of fusions between genes from the $E W S$ and ETS families are new transcription factors that influence cellular processes related to proliferation, apoptosis, autophagy, and cell viability [17]. 
It is generally considered that tumours occurring in children have very stable genomes, any mutations of genes associated with signalling pathways or chromatin modifications are uncommon in paediatric Ewing sarcomas [58]. Mutations in three genes are found - loss of STAG2 (15-17\%), CDKN2A (12-22\%), and TP5 3 (6-7\%); however, those mutations in STAG2 and $C D K N 2 A$ genes never occur together [58]. Loss of $S T A G 2$ expression (SA2 cohesin subunit) is associated with metastasis, so it could be the target of therapy [58]. However, the authors of this study point out that there are very few mutations in general, and besides the ones mentioned above, they are not repeated in different patients. There are some repeated abnormalities of chromosome numbers: an additional chromosome 8 in $50 \%$ of cases, slightly less (20-25\%) chromosome 2 and chromosome $1 \mathrm{q}$ as well as chromosome 20 in $10-20 \%$ of cases. Additional chromosome 1q and probably loss of chromosome $16 \mathrm{q}$ have negative prognostic significance [55].

It is still uncertain from which cells this tumour is derived [55], but due to the presence of characteristic gene fusions in virtually all cases, it is a very good object to study. The possible original cells are neural crest cells and mesoderm cells, and Ewing sarcoma precursor cells have also been found to be enriched in embryonic osteochondrogenic progenitor cells [59].

Similarly to many other diseases, association studies were undertaken for a large sample of 733 cases and over 1300 control persons, and some loci predisposing to the occurrence of Ewing sarcoma were detected - among others in 6p25.1, 20p11.22, and 20p11.23. Moreover, this study confirmed the previously obtained associations for loci in three other places [60]. Due to the fact that there are several of these sites, and the rare occurrence of the disease, this has no prognostic value, but it may better explain the mechanism of disease formation.

\section{Rhabdomyosarcoma}

According to the World Health Organisation classification, rhabdomyosarcoma (RMS) is a malignant tumour of skeletal muscle [2]. They constitute $40 \%$ of soft tissue sarcomas in children, but only $3-4 \%$ of all malignancies in this age group [17], although maybe even $5-10 \%$ [61]. Determining the type of malignancy is extremely important because the survival rate is within the range 35-90\%, depending on the subtype. Rhabdomyosarcomas are divided into several types; the most common of these are embryonal rhabdomyosarcomas (ERMS), occurring in about $60 \%$ of cases, and the next most common (20\%) are alveolar rhabdomyosarcomas (ARMS), consisting of cells having characteristics of embryonic skeletal cells. For ARMS the translocations connecting $P A X 3$ or $P A X 7$ with $F O X O$ are characteristic, leading to fusion gene formation [6], and in general are found in the majority of these tumours (77\%) [17]. Changes in ERMS are more diverse - CDKN2A/B deletions (23\%), FGRF4 activating mutations (20\%), $N F 1$ deletions (15\%), mutations activating genes from the ras family (12-42\%), and mutations in FGFR4 (9\%) and PIK3C A (5\%). In addition, 31\% of ERMS have high GLII expression [17]. In the same study it was stated that in RMS not otherwise specified mutation in the ras pathway occur in $35-45 \%$ of cases, and mutations in TP53 in 5-22\% and MDM2 amplification in $10-17 \%$ of cases.

A small proportion of ERMS and ARMS accompany other genetic neoplastic diseases - among others Beckwith-Wiedemann syndrome, Werner's syndrome, and Noonan's syndrome [6, 62].

It is believed that mutations are detected in sarcomas less frequently than in cancers, although the data given above do not confirm that. This view may change with the currently intensively used genomic sequencing approach - studies conducted in 1162 patients with sarcomas showed that 66 had mutations in genes such as TP53, $B R C A 2$, etc., and $25 \%$ had potentially pathogenic variants in one or more genes [3], but these data are given for different sarcomas. In contrast, mutations are observed in TP3 for RMS, ERMS (BRAF, CTNNB1, FGFR4, $K R A S$ ), and for ARMS mentioned above as a result of chromosomal translocation fusion Pax7/FOXO1 and Pax3/FOXO1 [63]. These fusions occur between chromosomes 1 and 13 or 2 and 13, respectively. As a result of $P A X 3-F O X O 1$ fusion, a strong transcriptional activator is formed; it is believed to contribute to the pathogenesis of ARMS by activating genes - among others PDGFR [17]. The list of genes whose expression is regulated by this fusion is long — there are over 200 of them [64].

However, additional changes in the genome are needed for tumorigenesis, including $M Y C N, C D K 4$, and MIT17-02 amplification, $C D K N 2 A$ deletion, or loss of heterozygosity in the $11 \mathrm{p} 15.5$ chromosome $[17,65]$. In patients with ARMS without the above fusions, mutations in the NRAS and PIK3CA genes are present [17]. Furthermore, it has recently been found that in non$P A X-F O X O$ RMS, the $R A S$ gene acting through the $R A F$ -MEK pathway (MAPK/ERK, mitogen activated protein kinase/extracellular signal regulated kinase) inhibits the differentiation of rhabdomyosarcoma cells into muscle cells by repression of myogenic agent $M Y O G$, needed for cell differentiation [66]. It is also known that the key regulator of ARMS growth is the SNAIL factor, which inhibits the expression of MYF5 and MYOD transcription factors; in human myoblasts inhibition of SNAIL causes an increase in the level of factors favouring differentiation into muscle and may have potential therapeutic application [67]. 
There are increasing numbers of studies analysing molecular changes in RMS, including proteome and epigenetic changes, and it has recently been found that ARMS occurs in more differentiated cells than ERMS, and that in RMS not only $R A S / M E K / E R K / C D K 4 / 6$ pathway is deregulated, but there are also disorders in the so-called Unfolded Protein Response (pathway associated with the reaction to the accumulation of improperly folded proteins) and in mitosis between the G2 and M stage [68].

The nature of RMS seems complicated; recently 29 genes have been identified that affect the development of this malignancy. Both suppressors and so-called driver genes controlling tumour growth are associated with different cellular processes - apoptosis, cell adhesion, DNA repair, protein folding, response to oxidative stress, and others [69].

In patients with metastatic ARMS the four-year survival is much better $(75 \%)$ for the $P A X 7-F O X O 1$ fusion, but only $8 \%$ for the $P A X 3-F O X O 1$ fusion [17].

In ERMS there is a loss of both alleles in the region of chromosome $11 \mathrm{p} 15.5$, in regions where a tumour suppressor or suppressors are located. There are also a variety of other changes in a number of chromosomal sites; in about $35 \%$ of cases there are also mutations in the $R A S$ gene family $[17,70]$ and additional mutations in TP53, MDM2, CDKN2A, GLI1, CTNNB1, and PRPN11 genes [17].

\section{Undifferentiated pleomorphic sarcoma and myxofibrosarcoma}

According to the World Health Organisation classification, myxofibrosarcoma (MFS) is referred to as a malignant fibroblastic/myofibroblastic tumour and undifferentiated pleomorphic sarcoma (UPS) as undifferentiated/unclassified sarcoma [2]. Tumours, such as undifferentiated pleomorphic sarcoma, do not have a clear pattern of differentiation or the normal tissue related to them is not known.

In alveolar soft tissue myxofibrosarcoma there was a rare occurrence of mutations in NF1 and TP53 genes [63].

In myxofibroma the following fusions are present: KIAA2026-NUDT11, CCBL1-ARL1, and AFF3-PHF1 (t[9;X][p24;p11]; t[9;12][q34;q23]; t[2;6] [q12;p21], respectively) [2].

Although these two types of malignancies will be discussed separately, it is justified to combine them in one chapter because the recently published genomic characteristics results for different sarcomas classify UPS and MFS as one group with a range of phenotypic differences [8]; these studies were extensive and included analyses of mRNA, microRNA, DNA sequences, methylation, and the number of individual gene cop- ies. It was found that the genes associated with the matrix are expressed at a higher level in MFS. In 10\% of cases, amplification of the gene CCNE1 was found, whereas VGLL3 was amplified in $11 \%$ of cases. They is interesting because the authors state that because these genes are related to the Hippo signalling pathway, so inhibitors of this pathway may be used in the therapy of MFS and UPS.

UPS is one of the most common sarcomas in older people; it is most common in patients between 50 and 70 years old, and rare in children. In general, tumours are located deeply, although recently a case of UPS with a skin location was also described [71]. The spectrum of mutations found in UPS has not been fully characterised; however, these tumour cells are quite similar to mesenchymal stem cells [72]. There are very few general studies on this malignancy, but the vast majority of literature consists of case reports.

Even the origin of these malignancies is not clear, because there is a suspicion that at least in some cases it may be a carcinoma and not a sarcoma. Moreover, because its classification is difficult due to the changing diagnostic criteria, these lesions are described, but this is not a homogeneous group. There are no characteristic changes for UPS, although the changes in chromosome number are frequent - both reduction and polyploidisation [73]. There are many different changes in individual regions of chromosomes, and region $12 \mathrm{q} 13-15$ seems to be particularly important.

In individual cases of more accurately tested UPS mutations in individual genes are detected - for example in $K R A S$ and PIK3CA in one patient [74], but it is certainly not characteristic for all cases, not even for the majority, contrary to changes in chromosome number and the amplification of individual parts of the genome.

Due to the fact that these malignancies are poorly characterised, it is difficult to consider targeted therapy, but there are some attempts in this direction. Using earlier data on activated protein kinase B (AKT) in $20 \%$ of patients with UPS, overexpression of which was correlated with poor survival [75], it has been shown that it is possible to inhibit cellular proliferation in vitro from UPS by using a combination of IGF1R/PI3K/mTOR pathway inhibitors and an IGF1R kinase inhibitor [76].

Recently 95 patients with UPS were screened to find possible mutations that would allow targeted therapies [77]. This study showed that classification to UPS is quite often faulty - ultimately only 18 patients had UPS and 44 had MFS, and only in one patient with UPS a mutation allowing consideration of targeted therapy was detected (PIK3CA mutation) [77], so it seems that UPS is not a candidate for diagnostics based on sequencing the patients' genomes.

MFS is also common in older people. Cytogenetic studies have shown frequent amplification of the $5 p$ 
chromosome region [72]. Expression of the ITGA10 gene, which encodes integrin- $\alpha$, is associated with poorer outcomes, it was also found that TRIO and RICTOR proteins, involved in the signalling pathway for this integrin, can be inhibited by RAC inhibitor (activated by the two proteins) and an mTOR inhibitor; addition of these proteins inhibited the growth of tumour cells in vitro [78]. The most recent studies have been conducted on 41 MFS tumours. Exome sequencing and methylation studies were performed for all of them, and for some (29) also RNA sequencing [79] and then 140 selected genes for over $100 \mathrm{MFSs}$ were examined. In total, 14 genes that control oncogenesis were detected, of which over $1 / 3$ could potentially be a target for therapies. In MFS there are frequent changes associated with signalling by $\mathrm{p} 53$ and genes associated with cell cycle checkpoints (51 and $43 \%$ of cases, respectively). The authors also found three patterns of MFS methylation, associated with control mutations and clinical outcomes, and having an influence on patient survival. Unlike UPS, it seems that MFS is definitely a more homogeneous malignancy, and there are good perspectives for using targeted therapies here.

In the same study, RNA sequencing was also performed, and in 29 tested samples 1653 transcripts were detected, resulting from the fusion of two genes, including in one of them the SCL37A-BRAF fusion; in additional experiments it was demonstrated that it induced tumours in nude mice, so it is a controlling gene for a specific MFS [79]. The study also showed some correlations of changes in genes regulating the cell cycle, with worse survival outcomes. It was interesting to note that mutations in the $G N A S$ gene seemed to protect against death caused by malignancy [79].

A large portion of MFS (14/30) overexpress MET [80] protein, and this is associated with the amplification of the $M E T$ gene and with polyploidisation of chromosome 7.

Another approach to the molecular analysis of sarcomas is to obtain cell cultures and conduct research on them. In general, unlike research related to DNA and RNA analysis, such work concerns only a few lines, and drawing conclusions from them is quite limited. On the other hand, it is possible to carry out studies on the effects of drugs, the ability of cells to invade, etc. One such study [81], carried out on cells from three patients, brought encouraging results for the CD109 marker in identifying more aggressive MFS.

\section{Osteosarcoma}

Genes encoding tumour suppressors including p53, Rb, RECQL4 (ATP-Dependent DNA helicase Q4/RecQ Like helicase 4), BLM (Bloom Syndrome RecQ Like helicase/DNA helicase, RecQ-Like Type 2), and WRN (Werner Syndrome RecQ helicase Like/DNA helicase/RecQ-Like Type 3) proteins play a special role in the pathogenesis of osteosarcoma (OS). These proteins play a key role in the development of OS in patients with Li-Fraumeni syndrome, hereditary retinoblastoma, Rothmund-Thomson, Bloom and Werner syndrome [82]. There are currently no drugs that allow the restoration of the function of the mutant $\mathrm{p} 53$ protein, although many compounds have been tested in preclinical studies [83]. Although osteosarcomas do not have specific translocations, in contrast to, for example Ewing sarcoma, OS cells carry numerous loss of heterozygosity $(\mathrm{LOH})$ lesions, reflecting the described variation in the number of gene copies in these tumours. While the OS have relatively few mutations in gene exons as compared to other solid tumours [84], the amount of amplification of genes in osteosarcoma is higher than for any other human malignancy. It is indicated that these are amplifications generated by chromothripsis for both paediatric and adult OS [85]. Circulating DNA released from OS cells including characteristic somatic mutations, such insertions, deletions, or translocations are detectable in the blood samples from OS patients. The mutations of the TP53 gene are particularly useful for determination in a liquid biopsy [86]. Due to numerous chromosomal abnormalities and mutations, the OS appears to be a tumour potentially responding to immunotherapy, and current studies of immune checkpoint inhibitors use anti-PD-1 and anti-CTLA-4, including nivolumab \pm ipilimumab (NCT02304458) and pembrolizumab (NCT02301039), as well as INF- $\alpha-2 b$ (NCT00134030) and L-MTP-PE (liposomal muramyl tripeptide phosphatidylethanolamine) (NCT00631631; NCT02441309) [87].

In recent years, several groups have performed OS sequencing, including whole genome sequencing (WGS) from 47 OS samples with pairs of healthy control tissues, whole exome sequencing (WES) from 111 samples with a set of healthy control tissues, and whole-transcriptome sequencing from 36 samples [88-90]. Unfortunately, most of the studies published on OS concern de facto paediatric cases, and the lists of genes considered important for the development of childhood OS and OS in adults probably differ [82], although recently conducted selected genome studies indicate that they may be significantly analogous [85]. In studies of samples from paediatric tumours (mainly subtype osteoblastic and chondroblastic) it has been shown that the majority ( $>70 \%$ ) of tumours carry the mutated TP53 or $R B$ gene. Furthermore, analysis of the genome indicated further genes in which mutations contribute to the development of overall survival, including genes responsible for: 1) controlling the cell cycle and apoptosis ( $p 53, R B 1$, $C D K N 2 A, C D K 4, M D M 2, M Y C, C A R D 11, C T N N D 1$, BLM, CCNE1, COPS3, PRKCA); 2) PI3K-mTOR and 
RAS signal pathways genes (EGFR, GNAQ, GNAS, ALK, PDGFRA, PDGFRB, PIK3CA, AKT2, PIK3R1, $P T E N, T S C 2$, VHL, $C B L)$; 3) Notch-signalling pathway genes (NOTCH1-4, MAML2, FBXW7, PDPK1, AKT1, $E 1 F 4 B)$; 4) proteins of DNA damage repair (BRCA1, BRCA2, MLH1, BAP1, ATM, WRN); 5) chromatin modification proteins ( $A T R X, F A N C E, R E C Q L 4$, $A R I D 1 A, E P 300)$; 6) transcription regulation genes (Runx1, GAS7,MLLT3); and others [82]. In turn, genetic tests in adults and adolescents $(<16$ years old) with OS showed that the genes regulating OS development in adults include TP53, PIK3CA (phosphatidylinositol-4,5-bisphosphate 3-kinase catalytic subunit alpha), AKT1 (AKT serine/threonine protein kinase 1), H3F3A (H3 histone family member 3A), SETD2 (SET domain containing 2) and $F B X W 7$ (F-box and WD repeat domain containing 7, E3 ubiquitin protein ligase). This study also indicated that genes regulating angiogenesis (TIE1 and KDR) can play an important role in OS development [84]. In addition, studies of adult tumours indicate IGF1 receptor (IGF1R) amplification in $14 \%$ of tumours [85]. In turn, research aimed at searching for diagnostic-prognostic biomarkers and analysing the level of gene expression in OS tumours led to the identification of characteristic profiles of protein expression and mRNA in OS cells. Deregulated levels of ErbB-2 (tyrosine kinase-type cell surface receptor HER2), cathepsin D, FBXW7 (F-box and WD repeat domain containing 7, the E3 ubiquitin protein ligase), microRNA miR-421, and HMGB1 (high-mobility group [non-histone chromosomal] protein 1) have been shown. It was also suggested that the expression of the Gla matrix protein may play a role in facilitating the spread of the tumour in metastatic lesions in the lungs [91]. A comparison of fresh biopsy material from the femoral and healthy femoral bone indicates that over 3300 genes are overexpressed and nearly 2000 have reduced expression in the OS. Among these genes, $B T N L 9, M M P 14, A B C A 10, A C A C B, C O L 11 A 1$, and $P K M 2$ have the highest difference in expression between tumour and normal bone. This study requires validation in a larger cohort of patients [92].

Currently, an interesting direction for research based on OS analysis is small RNA analysis, because it plays a regulatory role in relation to other genes. The characteristic small RNA deregulated in OS is miR-421. The expression level of miR-421 in serum is higher in OS patients than in healthy volunteers. In addition, miR-421 expression is higher in osteosarcoma tissues compared to adjacent normal tissues in $90 \%$ of OS patients. In addition, miR-421 expression levels in tissues from OS patients correlate with serum levels. Finally, patients with high miR-421 expression have a shorter overall survival than those with low expression, and miR-421 overexpression promotes proliferation, migration, and invasion of osteosarcoma cells. Other microRNAs of potential significance in the pathophysiology of OS include: miRNA-129-5p (miR-129-5p), miR-330-3p, miR-365, or miR-491-3p [93]. miR-21, -34a, -143, -148a, -195a, $-199 \mathrm{a}-3 \mathrm{p}$, and -382 regulate the activity of MAPK and PI3K/Akt signalling pathways in OS [94]. Determining the diagnostic and prognostic significance of small RNA in OS requires meta-analysis and validation in prospective studies. This is important as small RNAs are easily detectable in the blood of patients and can potentially be used to develop diagnostic tests [95].

Functional research in the field of basic sciences describes the number of mutations and their order necessary/minimal for OS development. An inductor gene that can cause bone malignancy is classified as primary. The group of primary OS inducers includes the following genes: TP53, NOTCH1, MYC, FOS, NF2, WIF1, BRCA2, APC, PTCH1, and PRKAR1A. However, the penetration of each of the above genes are different. Damage to TP53 and NOTCH genes can induce tumour formation with close to $100 \%$ penetration, while mutations at WIF1 and BRCA2 can induce OS development in only a small percentage of patients. A gene which perturbation cannot independently initiate a malignant process in the bone is classified as a synergistic gene. A deregulated synergistic gene can accelerate tumour initiation and growth, but it can also affect disease progression through germline mutation before the primary gene is damaged by somatic mutation. The group of synergistic genes in OS includes RB1, TWIST, PTEN, and JUN [82].

The meta-analysis of available proteomic data comparing protein expression between OS cells and healthy osteoblasts revealed a list of proteins that are potential targets of drugs currently available on the market. Although this is a preliminary analysis, the authors suggest that in vitro and in vivo studies should be carried out to evaluate the potential benefit of use of the indicated substance against OS. Proteins indicated as potential drug targets in OS include DNMT1 (DNA [cytosine-5]-methyltransferase 1) - target for azacytidine (Vidaza) and decitabine (Dacogen); ERBB2 (receptor tyrosine-protein kinase erbB-2) - a target for trastuzumab (Herceptin) and lapatinib (Tycerb) afatinib (GIOTRIF/ /GILOTRIF), pertuzumab (PERJETA); GSR (mitochondrial glutathione reductase) - target for carmustine (GLIADEL ${ }^{\circledR}$ WAFER); HDAC1 (histone deacetylase 1) — target for vorinostat (Zolinza); HDAC2 (Histone deacetylase 2) - target for romidepsin (Istodax); KIT (mast/stem cell growth factor receptor kit) — target for imatinib (Gleevec), sorafenib (Nexavar), sunitinib (Sutent), pazopanib (Votrient), dasatinib (Sprycel), axitinib (Inlyta) and nilotinib (Tasigna); FGFR1 (Fibroblast growth factor receptor 1) - target for lenvatinib (Lenvima); MET (Hepatocyte growth factor receptor) 
- target for cabozantinib (COMETRIQ), crizotinib (XALKORI); MTOR (serine/threonine protein kinase mTOR) - target for temsirolimus (Torisel), everolimus (Afinitor); PARP1 (poly [ADP-ribose] polymerase 1) - target for olaparib (AZD2281); PDGFR $\alpha$ (platelet-derived growth factor receptor alpha) - target for imatinib (Gleevac), sorafenib (Nexavar), sunitinib (Sutent), pazopanib (Votrient), nilotinib (Tasigna), axitinib (Inlyta), and dasatinib (Sprycel) and PSMC2 (26S protease regulators subunit 7) - targets for bortezomib (Velcade) [96]. The list of the above potential targets for drugs also includes those regulated by drugs currently evaluated in phase I/II clinical trials in OS, including bevacizumab (NCT00667342), sorafenib (NCT00889057, NCT01804374, regorafenib (NCI02048371), pazopanib (NCT01956669; NCT01759303), cabozantinib (NCT02243605), sirolimus (NCT02517918), everolimus (RAD001) (NCT01804374), and glembatumumab vedotin (NCT02487979) [87]. An interesting potential target for treatment in OS is also GD2 disialoganglioside. It has been shown that anti-GD2 therapy - chimeric anti-GD2 antibody dinutuximab - improves survival outcomes in patients with neuroblastoma, and almost all OS cases express a large amount of GD2. Currently, studies are being conducted with several anti-GD2 molecules, including dinutuximab (NCT02484443), Hu3F8 (NCT02502786), and Hu14. 18K322A (NCT00743496), and cell therapy with anti-GD2 lymphocytes (NCT02173093, NCT02107963) [87].

\section{Chondrosarcoma}

Although the biology of chondrosarcoma (CHS) is still unclear, it is known that there is an increased number of genetic aberrations together with dedifferentiation of CHS from low to high grade. The role of p53 in the pathology in CHS remains unexplained, but the presence of $\mathrm{p} 53$ protein overexpression, $17 \mathrm{p} 1$ chromosomal aberration, and TP53 mutations present in almost all poorly differentiated CHS suggests that TP53 mutation/mutations are a late event associated with CHS progression. This is also confirmed by $12 \mathrm{q} 13$ (MDM2) amplification and loss of 9p21 (CDKN21/p16/INK4A and INK4A-p14ARF) [97]. At the same time, irregularities of c- $M Y C$ appear to occur in the early stages of tumorigenesis in all chondrosarcomas, and overexpression of metalloproteinases MMP-2, MMP-MT1, and TIMP2 and abnormal methylation of p16 and E-cadherin present in anaplastic cells of dedifferentiated CHS [98]. In addition, in $69 \%$ of patients with conventional CHS and $44 \%$ with dedifferentiated CHS, a high phosphorylation of S6 kinase, a surrogate of the PI3K-mTOR pathway activity, was detected [99]. BEZ235 - an inhibitor of PI3K and mTOR - significantly inhibited division of
CHS cell lines and CHS tumour growth in an animal model, suggesting that the inhibition of PI3K/mTOR is a potentially new therapeutic strategy, which could be evaluated in the early phases and could be possible also in patients after failure of previous treatment with kinase inhibitors (pazopanib) [100, 101].

Recent studies have shown frequent occurrence of mutations in $I D H 1$ (isocitrate dehydrogenase 1) or IDH2 genes in almost half of chondrosarcomas, including the prognostic significance of these mutations [102]. IDH proteins encoded by the $I D H$ genes catalyse oxidative decarboxylation of isocitrate, producing $\alpha \mathrm{KG}$ and $\mathrm{CO}_{2}$ in the citric acid cycle (CAC), also called the Krebs cycle. It is known that these mutations result in the production of D-2 hydroxyglutarate (2HG) from $\alpha \mathrm{KG}$ conversion (alpha-ketoglutarate). 2HG accumulates in the cells and inhibits the activity of $\alpha \mathrm{KG}$-dependent enzymes, leading to hypermethylation of DNA and histones, which results in a change in the expression of genes associated with oncogenesis. 2HG inhibits TET2 (TET methylcytosine dioxygenase 2) the activity of a DNA-modifying enzyme dependent on $\alpha \mathrm{KG}$, responsible for DNA demethylation. Thus, $2 \mathrm{HG}$ causes hypermethylation of DNA (by inhibition of demethylation). 2HG also inhibits $\alpha$ KG-dependent histone demethylase of JHKDM (JmjC-domain containing histone lysine a demethylases). JHKDM modifies chromatin and thereby regulates gene expression. The IDH2 mutation has been shown to induce 2HG-dependent DNA hypermethylation in chondrosarcoma cells, which inhibits mesenchymal differentiation. Treatment with a 5-azacitidine, a demethylating compound, can potentially reverse this block of differentiation. There are ongoing clinical trials evaluating the clinical activity of novel IDH inhibitors. AG-221 - an oral IDH2 inhibitor - is currently being tested in phase I/II studies in patients with chondrosarcoma with the $I D H 2$ mutation (NCT02273739). Inhibitors IDH AG-881 and AG-120 are also being evaluated in phase I studies in chondrosarcoma with $I D H 1$ and/or IDH2 mutation (NCT02481154/NCT02073994); combination of metformin with chloroquine in CHS patients with $I D H 1 / 2$ mutations is also undergoing clinical trials (NCT02496741) [99].

Proteomic analysis of the entire chondrosarcoma kinome revealed that the AKT1/GSK3B pathway was clearly active in the case of CHS. In addition, the PDGFR pathway and the Src kinase family were active; however, this activation did not translate into effectiveness of inhibiting the proliferation of CHS cells by imatinib or dasatinib except an in vitro model, and the objective response rates in the phase II studies were low $[103,104]$. In CHS, the hypermutability of the main cartilage collagen gene $C O L 2 A 1$ was identified, including insertions, deletions, and rearrangements in $37 \%$ of cases. The described mutations may interfere with 
normal collagen biosynthesis. In addition, mutations were identified in $I D H 1$ or IDH2 (59\% of cases), and TP53 (20\%) genes, RB1 pathway (33\%), and Hedgehog pathway $(18 \%)$ [105].

The IHH (Indian Hedgehog) pathway and the parathyroid hormone-related peptide (PTHrP) pathway play a key role in the differentiation of healthy chondrocytes, and it has been proven that constitutive IHH signalling plays a key role in the pathogenesis of chondrosarcomas. Abnormal activation of this pathway leads to continuous signals from $\mathrm{IHH}$ that induce chondrocyte proliferation and the secretion of PTHrP from chondrocytes into the extracellular matrix. By auto- and paracrine signalling, PTHrP mediates the inhibition of chondrocyte differentiation and apoptosis, thus maintaining cells in the state of cell division [99]. While preclinical data on the activity of IPI-926 (saridegib - oral Hedgehog pathway inhibitor) indicated good activity of this compound, clinical data from a phase II study in patients with advanced chondrosarcoma were not satisfactory $[106,107]$. Similarly, vismodegib (GDC-0449) treatment assessed in a phase II study did not bring the expected results; the median progression-free survival (mPFS) was only 3.5 months, and the median overall survival (mOS) was 12.4 months [108]. These disappointing clinical outcomes may indicate a ligand-independent activation of the Hh pathway in CHS, which may occur in the case of loss of PTCH function mutation or SMO mutation, causing loss of function and activation of the downstream pathway [99].

\section{References}

1. Taylor BS, Barretina J, Maki RG, et al. Advances in sarcoma genomics and new therapeutic targets. Nat Rev Cancer. 2011; 11(8): 541-557, doi: 10.1038/nrc3087, indexed in Pubmed: 21753790.

2. Sbaraglia M, Dei Tos AP. The pathology of soft tissue sarcomas. Radiol Med. 2018 [Epub ahead of print]: 1-16, doi: 10.1007/s11547-018-08827, indexed in Pubmed: 29948548.

3. Ballinger ML, Goode DL, Ray-Coquard I, et al. International Sarcoma Kindred Study. Monogenic and polygenic determinants of sarcoma risk: an international genetic study. Lancet Oncol. 2016 17(9): 1261-1271, doi: 10.1016/S1470-2045(16)30147-4, indexed in Pubmed: 27498913.

4. Rutkowski P, Świtaj T. Bone sarcomas. Oncol Clin Pract. 2018; 14(3): 115-128, doi: 10.5603/OCP.2018.0018.

5. Rutkowski P, Ługowska I. Soft tissue sarcomas in adults. Oncol Clin Pract. 2017; 13(5): 181-201, doi: 10.5603/OCP.2017.0025.

6. Farid M, Ngeow J. Sarcomas Associated With Genetic Cancer Predisposition Syndromes: A Review. Oncologist. 2016; 21(8): 1002-1013 doi: 10.1634/theoncologist.2016-0079, indexed in Pubmed: 27401891.

7. Groisberg R, Hong DS, Holla V, et al. Clinical genomic profiling to identify actionable alterations for investigational therapies in patients with diverse sarcomas. Oncotarget. 2017; 8(24): 39254-39267, doi: 10.18632/oncotarget.16845, indexed in Pubmed: 28424409

8. The Cancer Genome Atlas Research Network. Cancer Genome Atlas Research, Comprehensive and Integrated Genomic Characterization of Adult Soft Tissue Sarcomas. Cell. 2017; 171(4): 950-965.e28, doi: 10.1016/j.cell.2017.10.014

9. Hameed M. Pathology and genetics of adipocytic tumors. Cytogenet Genome Res. 2007; 118(2-4): 138-147, doi: 10.1159/000108294, indexed in Pubmed: 18000364.

10. Arrigoni G, Doglioni C. Atypical lipomatous tumor: molecular characterization. Curr Opin Oncol. 2004; 16(4): 355-358, doi: 10.1097/01. cco.0000127878.85125.53.
11. D'Angelo A, Garzia L, André A, et al. Prune cAMP phosphodiesterase binds nm23- $\mathrm{H} 1$ and promotes cancer metastasis. Cancer Cell. 2004; 5(2): 137-149, doi: 10.1016/s1535-6108(04)00021-2, indexed in Pubmed: 14998490

12. Cin PD, Kools P, Sciot R, et al. Cytogenetic and fluorescence in situ hybridization investigation of ring chromosomes characterizing a specific pathologic subgroup of adipose tissue tumors. Cancer Genet Cytogenet. 1993; 68(2): 85-90, doi: 10.1016/0165-4608(93)90001-3.

13. Crago AM, Socci ND, DeCarolis P, et al. Copy number losses define subgroups of dedifferentiated liposarcoma with poor prognosis and genomic instability. Clin Cancer Res. 2012; 18(5): 1334-1340, doi: 10.1158/1078-0432.CCR-11-2820, indexed in Pubmed: 22241790.

14. Sandberg AA. Updates on the cytogenetics and molecular genetics of bone and soft tissue tumors: liposarcoma. Cancer Genet Cytogenet. 2004; 155(1): 1-24, doi: 10.1016/j.cancergencyto.2004.08.005, indexed in Pubmed: 15527898

15. Dei Tos AP, Doglioni P, Piccinin S, et al. Molecular abnormalities of the p53 pathway in dedifferentiated liposarcoma. J Pathol. 1997; 181(1): 8-13.

16. Snyder EL, Sandstrom DJ, Law K, et al. c-Jun amplification and overexpression are oncogenic in liposarcoma but not always sufficient to inhibit the adipocytic differentiation programme. J Pathol. 2009; 218(3): 292-300, doi: 10.1002/path.2564, indexed in Pubmed: 19449367.

17. Hoang NT, Acevedo LA, Mann MJ, et al. A review of soft-tissue sarcomas: translation of biological advances into treatment measures. Cancer Manag Res. 2018; 2018(10): 1089-1114, doi: 10.2147/CMAR. S159641, indexed in Pubmed: 29785138.

18. Singer S, Socci ND, Ambrosini G, et al. Gene expression profiling of liposarcoma identifies distinct biological types/subtypes and potential therapeutic targets in well-differentiated and dedifferentiated liposarcoma. Cancer Res. 2007; 67(14): 6626-6636, doi: 10.1158/0008-5472. CAN-07-0584, indexed in Pubmed: 17638873.

19. Limon J, Turc-Carel C, Cin PD, et al. Recurrent chromosome translocations in liposarcoma. Cancer Genet Cytogenet. 1986; 22(1): 93-94, doi: 10.1016/0165-4608(86)90143-3.

20. Aman $P$, Ron D, Mandahl N, et al. Rearrangement of the transcription factor gene CHOP in myxoid liposarcomas with $t(12 ; 16)(q 13 ; p 11)$. Genes Chromosomes Cancer. 1992; 5(4): 278-285, indexed in Pubmed: 1283316.

21. Kuroda M, Ishida T, Horiuchi $H$, et al. Chimeric TLS/FUS-CHOP gene expression and the heterogeneity of its junction in human myxoid and round cell liposarcoma. Am J Pathol. 1995; 147(5): 1221-1227. indexed in Pubmed: 7485386.

22. Panagopoulos I, Lassen $C$, Isaksson $M$, et al. Characteristic sequence motifs at the breakpoints of the hybrid genes FUS/CHOP, EWS/CHOP and FUS/ERG in myxoid liposarcoma and acute myeloid leukemia. Oncogene. 1997; 15(11): 1357-1362, doi: 10.1038/sj.onc.1201281, indexed in Pubmed: 9315104.

23. Antonescu CR, Elahi A, Humphrey M, et al. Specificity of TLS-CHOP rearrangement for classic myxoid/round cell liposarcoma: absence in predominantly myxoid well-differentiated liposarcomas. J Mol Diagn. 2000; 2(3): 132-138, doi: 10.1016/S1525-1578(10)60628-9, indexed in Pubmed: 11229517

24. Panagopoulos I, Åman P, Mertens F, et al. Genomic PCR detects tumor cells in peripheral blood from patients with myxoid liposarcoma. Gene Chromosome and Canc. 1996; 17(2): 102-107, doi: 10.1002/ (sici)1098-2264(199610)17:2<102::aid-gcc5>3.0.co;2-9.

25. Demicco EG, Torres KE, Ghadimi MP et al. Involvement of the PI3K /Akt pathway in myxoid/round cell liposarcoma. Mod Pathol. 2012; 25(2): 212-221, doi: 10.1038/modpathol.2011.148, indexed in Pubmed: 22020193

26. Costa A, Daidone MG, Daprai L, et al. Telomere maintenance mechanisms in liposarcomas: association with histologic subtypes and disease progression. Cancer Res. 2006; 66(17): 8918-8924, doi: 10.1158/0008-5472.CAN-06-0273, indexed in Pubmed: 16951210.

27. Fritz B, Schubert F, Wrobel G, et al. Microarray-based copy number and expression profiling in dedifferentiated and pleomorphic liposarcoma. Cancer Res. 2002 62(11) : 2993-2998, indexed in Pubmed: 12036902.

28. Larramendy ML, Kaur S, Svarvar C, et al. Gene copy number profiling of soft-tissue leiomyosarcomas by array-comparative genomic hybridization. Cancer Genet Cytogenet. 2006; 169(2): 94-101, doi: 10.1016/j.cancergencyto.2006.01.008, indexed in Pubmed: 16938566.

29. Wang R, Lu YJ, Fisher C, et al. Characterization of chromosome aberrations associated with soft-tissue leiomyosarcomas by twenty-four-color karyotyping and comparative genomic hybridization analysis. Gene Chromosome Canc. 2001; 31(1): 54-64, doi: 10.1002/gcc.1118, indexed in Pubmed: 11284036

30. Otaño-Joos M, Mechtersheimer G, Ohl S, et al. Detection of chromosomal imbalances in leiomyosarcoma by comparative genomic 
hybridization and interphase cytogenetics. Cytogenet Cell Genet. 2000; 90(1-2): 86-92, doi: 10.1159/000015640, indexed in Pubmed: 11060455 .

31. Derré J, Lagacé R, Nicolas A, et al. Leiomyosarcomas and Most Malignant Fibrous Histiocytomas Share Very Similar Comparative Genomic Hybridization Imbalances: An Analysis of a Series of 27 Leiomyosarcomas. Lab Invest. 2001; 81(2): 211-215, doi: 10.1038/labinvest.3780229.

32. Wang R, Titley JC, Lu YJ, et al. Loss of 13q14-q21 and gain of 5p14-pter in the progression of leiomyosarcoma. Mod Pathol. 2003; 16(8): 778-785, doi: 10.1097/01.MP.0000083648.45923.2B, indexed in Pubmed: 12920222.

33. Riva P, Dalprá L, Gualandri $\mathrm{V}$, et al. 19p deletion in recurring leiomyosarcoma lesions from the same patient. Cancer Genet Cytogenet. 2000; 119(2): 102-108, doi: 10.1016/s0165-4608(99)00222-8, indexed in Pubmed: 10867143

34. Kawaguchi Ki, Oda $Y$, Saito $T$, et al. Mechanisms of inactivation of the p16INK4a gene in leiomyosarcoma of soft tissue: decreased p16 expression correlates with promoter methylation and poor prognosis. J Pathol. 2003; 201(3): 487-495, doi: 10.1002/path.1419, indexed in Pubmed: 14595762.

35. Henriksen J, Aagesen TH, Maelandsmo GM, et al. Amplification and overexpression of COPS3 in osteosarcomas potentially target TP53 for proteasome-mediated degradation. Oncogene. 2003; 22(34): 5358-5361, doi: 10.1038/sj onc. 1206671, indexed in Pubmed: 12917637.

36. Ragazzini P, Gamberi G, Pazzaglia L, et al. Amplification of CDK4 MDM2, SAS and GLI genes in leiomyosarcoma, alveolar and embryonal rhabdomyosarcoma. Histol Histopathol. 2004; 19(2): 401-411, doi: 10.14670/HH-19.401, indexed in Pubmed: 15024701.

37. Hernando E, Charytonowicz E, Dudas ME, et al. The AKT-mTOR pathway plays a critical role in the development of leiomyosarcomas. Nat Med. 2007; 13(6): 748-753, doi: 10.1038/nm1560, indexed in Pubmed: 17496901.

38. Grossmann A, Layfield L, Randall R. Classification, Molecular Characterization, and the Significance ofPtenAlteration in Leiomyosarcoma. Sarcoma. 2012; 2012: 1-8, doi: 10.1155/2012/380896

39. Pérot G, Derré J, Coindre JM, et al. Strong smooth muscle differentiation is dependent on myocardin gene amplification in most human retroperitoneal leiomyosarcomas. Cancer Res. 2009; 69(6): 2269-2278, doi: 10.1158/0008-5472.CAN-08-1443, indexed in Pubmed: 19276386

40. Yang J, Du X, Chen K, et al. Genetic aberrations in soft tissue leiomyosarcoma. Cancer Lett. 2009; 275(1): 1-8, doi: 10.1016/j. canlet.2008.06.013, indexed in Pubmed: 18649996.

41. Guo X, Jo VY, Mills AM, et al. Clinically Relevant Molecular Subtypes in Leiomyosarcoma. Clin Cancer Res. 2015; 21(15): 3501-3511, doi: 10.1158/1078-0432.CCR-14-3141, indexed in Pubmed: 25896974.

42. El Beaino M, Araujo DM, Lazar AJ, et al. Synovial Sarcoma: Advances in Diagnosis and Treatment Identification of New Biologic Targets to Improve Multimodal Therapy. Ann Surg Oncol. 2017; 24(8): 2145-2154 doi: 10.1245/s10434-017-5855-x, indexed in Pubmed: 28397189

43. Pan M, Merchant M. Risk Factors Including Age, Stage and Anatomic Location that Impact the Outcomes of Patients with Synovial Sarcoma Med Sci (Basel). 2018; 6(1): 21, doi: 10.3390/medsci6010021, indexed in Pubmed: 29509716.

44. Rao UNM, Cieply K, Sherer C, et al. Correlation of Classic and Molecular Cytogenetic Alterations in Soft-Tissue Sarcomas: Analysis of 46 Tumors With Emphasis on Adipocytic Tumors and Synovial Sarcoma. Appl Immunohistochem Mol Morphol. 2017; 25(3): 168-177, doi: 10.1097/PAl.0000000000000294, indexed in Pubmed: 26808135

45. Lagarde P, Przybyl J, Brulard C, et al. Chromosome instability accounts for reverse metastatic outcomes of pediatric and adult synovial sarcomas. J Clin Oncol. 2013; 31(5): 608-615, doi: 10.1200/JCO.2012.46.0147, indexed in Pubmed: 23319690.

46. Przybyl J, Sciot R, Wozniak A, et al. Metastatic potential is determined early in synovial sarcoma development and reflected by tumor molecular features. Int J Biochem Cell Biol. 2014; 53: 505-513, doi: 10.1016/j. biocel.2014.05.006, indexed in Pubmed: 24842110.

47. Nielsen TO, Poulin NM, Ladanyi M. Synovial sarcoma: recent discoveries as a roadmap to new avenues for therapy. Cancer Discov. 2015; 5(2): 124-134, doi: 10.1158/2159-8290.CD-14-1246, indexed in Pubmed: 25614489.

48. Noujaim J, Thway K, Bajwa Z, et al. Epithelioid Sarcoma: Opportunities for Biology-Driven Targeted Therapy. Frontiers in Oncology. 2015 5(186): 1-11, doi: 10.3389/fonc.2015.00186.

49. Thway K, Jones RL, Noujaim J, et al. Epithelioid Sarcoma: Diagnostic Features and Genetics. Adv Anat Pathol. 2016; 23(1): 41-49, doi 10.1097/PAP.0000000000000102, indexed in Pubmed: 26645461.

50. Modena P, Lualdi E, Facchinettii F, et al. SMARCB1/INI1 tumor suppressor gene is frequently inactivated in epithelioid sarcomas. Cance Res. 2005; 65(10): 4012-4019, doi: 10.1158/0008-5472.CAN-04-3050.
51. Sápi Z, Papp G, Szendrői M, et al. Epigenetic regulation of SMARCB1 By miR-206, -381 and $-671-5 p$ is evident in a variety of SMARCB1 immunonegative soft tissue sarcomas, while miR-765 appears specific for epithelioid sarcoma. A miRNA study of 223 soft tissue sarcomas. Gene Chromosome Canc. 2016; 55(10): 786-802, doi: 10.1002/gcc.22379, indexed in Pubmed: 27223121

52. Kohashi K, Oda Y. Oncogenic roles of SMARCB1/INI1 and its deficient tumors. Cancer Sci. 2017; 108(4): 547-552, doi: 10.1111/cas.13173, indexed in Pubmed: 28109176

53. Klochendler-Yeivin A, Picarsky E, Yaniv M. Increased DNA damage sensitivity and apoptosis in cells lacking the Snf5/Ini1 subunit of the SWI/SNF chromatin remodeling complex. Mol Cell Biol. 2006; 26(7): 2661-2674, doi: 10.1128/MCB.26.7.2661-2674.2006, indexed in Pubmed: 16537910

54. Isakoff MS, Sansam CG, Tamayo P, et al. Inactivation of the Snf5 tumor suppressor stimulates cell cycle progression and cooperates with p53 loss in oncogenic transformation. Proc Natl Acad Sci U S A. 2005; 102(49): 17745-17750, doi: 10.1073/pnas.0509014102, indexed in Pubmed: 16301525 .

55. Grünewald TGP, Cidre-Aranaz F, Surdez D, et al. Ewing sarcoma. Nat Rev Dis Primers. 2018; 4(1): 5.

56. Kim SK, Park YK. Ewing sarcoma: a chronicle of molecular pathogenesis. Hum Pathol. 2016; 55: 91-100, doi: 10.1016/j.humpath.2016.05.008, indexed in Pubmed: 27246176.

57. Vidya Rani PS, Shyamala K, Girish HC, et al. Pathogenesis of Ewing sarcoma: A review. J Adv Res. 2015; 2: 164-168, doi: 10.15713/ins. jcri.70

58. Crompton BD, Stewart C, Taylor-Weiner A et al. The genomic landscape of pediatric Ewing sarcoma. Cancer Discov. 2014; 4(11) 1326-1341, doi: 10.1158/2159-8290.CD-13-1037, indexed in Pubmed: 25186949.

59. Tanaka M, Yamazaki Y, Kanno Y, et al. Ewing's sarcoma precursors are highly enriched in embryonic osteochondrogenic progenitors. J Clin Invest. 2014; 124(7): 3061-3074, doi: 10.1172/JCl72399.

60. Machiela MJ, Grünewald TGP, Surdez D, et al. Genome-wide association study identifies multiple new loci associated with Ewing sarcoma susceptibility. Nat Commun. 2018; 9(1): 3184, doi: 10.1038/s41467-018-05537-2.

61. Dziuba I, Kurzawa P Dopierała M, et al. Rhabdomyosarcoma in children - current pathologic and molecular classification. Pol J Pathol. 2018; 69(1): 20-32, doi: 10.5114/pjp.2018.75333, indexed in Pubmed: 29895123

62. Coffin CM, Davis JL, Borinstein SC. Syndrome-associated soft tissue tumours. Histopathology. 2014; 64(1): 68-87, doi: 10.1111/his.12280, indexed in Pubmed: 24236688

63. Potter JW, Jones KB, Barrott JJ Sarcoma - The standard-bearer in cancer discovery. Crit Rev Oncol Hematol. 2018; 126: 1-5, doi: 10.1016/j.critrevonc.2018.03.007, indexed in Pubmed: 29759550.

64. Akaike K, Suehara Y, Kohsaka S, et al. PPP2R1A regulated by PAX3/ /FOXO1 fusion contributes to the acquisition of aggressive behavior in PAX3/FOXO1-positive alveolar rhabdomyosarcoma. Oncotarget. 2018; 9(38): 25206-25215, doi: 10.18632/oncotarget.25392, indexed in Pubmed: 29861864

65. Shern JF, Chen L, Chmielecki J, et al. Comprehensive Genomic Analysis of Rhabdomyosarcoma Reveals a Landscape of Alterations Affecting a Common Genetic Axis in Fusion-Positive and Fusion-Negative Tumors. Cancer Discovery. 2014; 4(2): 216-231, doi: 10.1158/21598290.cd-13-0639.

66. Yohe ME, Gryder BE, Shern JF, et al. MEK inhibition induces MYOG and remodels super-enhancers in RAS-driven rhabdomyosarcoma. Sci Transl Med. 2018; 10(448), doi: 10.1126/scitransImed.aan4470, indexed in Pubmed: 29973406.

67. Skrzypek K, Kusienicka A, Trzyna E, et al. SNAIL is a key regulator of alveolar rhabdomyosarcoma tumor growth and differentiation through repression of MYF5 and MYOD function. Cell Death Dis. 2018; 9(6): 643, doi: 10.1038/s41419-018-0693-8, indexed in Pubmed: 29844345

68. Stewart E, McEvoy J, Wang H, et al. St. Jude Children's Research Hospital - Washington University Pediatric Cancer Genome Project. Identification of Therapeutic Targets in Rhabdomyosarcoma through Integrated Genomic, Epigenomic, and Proteomic Analyses. Cancer Cell. 2018; 34(3): 411-426.e19, doi: 10.1016/j.ccell.2018.07.012, indexed in Pubmed: 30146332

69. Xu L, Zheng Y, Liu J, et al. Integrative Bayesian Analysis Identifies Rhabdomyosarcoma Disease Genes. Cell Rep. 2018; 24(1): 238-251, doi: 10.1016/j.celrep.2018.06.006

70. Stratton MR, Fisher C, Gusterson BA, et al. Detection of point mutations in $\mathrm{N}$-ras and $\mathrm{K}$-ras genes of human embryonal rhabdomyosarcomas using oligonucleotide probes and the polymerase chain reaction. Cancer Res. 1989; 49(22): 6324-6327.

71. Paiva AC, Abreu MA, Souza MP. Undifferentiated pleomorphic sarcoma An Bras Dermatol. 2018; 93(1): 154-155, doi: 10.1590/abd18064841.20186613, indexed in Pubmed: 29641724. 
72. Widemann BC, Italiano A. Biology and Management of Undifferentiated Pleomorphic Sarcoma, Myxofibrosarcoma, and Malignant Periphera Nerve Sheath Tumors: State of the Art and Perspectives. J Clin Oncol. 2018; 36(2): 160-167, doi: 10.1200/JCO.2017.75.3467, indexed in Pubmed: 29220302

73. Sanei B, Kefayat A, Samadi M, et al. Undifferentiated Pleomorphic Sarcoma of Pancreas: A Case Report and Review of the Literature for the Last Updates. Case Rep Med. 2018; 2018: 1-6, doi 10.1155/2018/1510759, indexed in Pubmed: 29955231.

74. Li B, Li Li, Li X, et al. Undifferentiated pleomorphic sarcoma with co-existence of KRAS/PIK3CA mutations. Int J Clin Exp Pathol. 2015 8(7): 8563-8567, indexed in Pubmed: 26339434.

75. Lahat G, Zhang P, Zhu QS, et al. The expression of c-Met pathway components in unclassified pleomorphic sarcoma/malignant fibrous histiocytoma (UPS/MFH): a tissue microarray study. Histopathology. 2011; 59(3): 556-561, doi: 10.1111/j.1365-2559.2011.03946.x, indexed in Pubmed: 22034893

76. May CD, Landers SM, Bolshakov S, et al. Co-targeting PI3K, mTOR, and IGF1R with small molecule inhibitors for treating undifferentiated pleomorphic sarcoma. Cancer Biol Ther. 2017; 18(10): 816-826, doi 10.1080/15384047.2017.1373230, indexed in Pubmed: 29099264.

77. Lewin J, Garg S, Lau BY, et al. Identifying actionable variants using nex generation sequencing in patients with a historical diagnosis of undifferentiated pleomorphic sarcoma. Int J Cancer. 2018; 142(1): 57-65 doi: 10.1002/ijc.31039, indexed in Pubmed: 28891048.

78. Okada T, Lee AY, Qin LX, et al. Integrin- $\alpha 10$ Dependency Identifies RAC and RICTOR as Therapeutic Targets in High-Grade Myxofibrosarcoma Cancer Discov. 2016; 6(10): 1148-1165, doi: 10.1158/2159-8290.CD15-1481, indexed in Pubmed: 27577794

79. Ogura K, Hosoda F, Arai Y, et al. Integrated genetic and epigenetic analysis of myxofibrosarcoma. Nat Commun. 2018; 9(1): 2765, doi: 10.1038/s41467-018-03891-9, indexed in Pubmed: 30018380.

80. Ma S, Fan L, Liu Y, et al. MET-overexpressing myxofibrosarcoma frequently exhibit polysomy of chromosome 7 but not MET amplification, especially in high-grade cases: clinical and pathological review of 30 myxofibrosarcoma cases. Diagn Pathol. 2018; 13(1): 56, doi: 10.1186/s13000-018-0733-9, indexed in Pubmed: 30126419.

81. De Vita A, Recine F, Mercatali L, et al. Myxofibrosarcoma primary cultures: molecular and pharmacological profile. Ther Adv Med Oncol. 2017; 9(12): 755-767, doi: 10.1177/1758834017737472, indexed in Pubmed: 29449896.

82. Rickel K, Fang F, Tao J. Molecular genetics of osteosarcoma. Bone. 2017 102: 69-79, doi: 10.1016/j.bone.2016.10.017, indexed in Pubmed: 27760307.

83. Ribeiro CJA, Rodrigues CMP, Moreira R, et al. Chemical Variations on the p53 Reactivation Theme. Pharmaceuticals (Basel). 2016; 9(2) 1-33, doi: 10.3390/ph9020025, indexed in Pubmed: 27187415.

84. Joseph CG, Hwang $H$, Jiao $Y$, et al. Exomic analysis of myxoid liposarcomas, synovial sarcomas, and osteosarcomas. Gene Chromosome Canc. 2014; 53(1): 15-24, doi: 10.1002/gcc.22114, indexed in Pubmed: 24190505.

85. Behjati S, Tarpey PS, Haase K, et al. Recurrent mutation of IGF signalling genes and distinct patterns of genomic rearrangement in osteosarcoma. Nat Commun. 2017; 8: 1-8, doi: 10.1038/ncomms15936 indexed in Pubmed: 28643781.

86. Barris DM, Weiner SB, Dubin RA, et al. Detection of circulating tumor DNA in patients with osteosarcoma. Oncotarget. 2018: 9(16): 12695 12704, doi: 10.18632/oncotarget.24268, indexed in Pubmed: 29560102

87. Bishop MW, Janeway KA, Gorlick R. Future directions in the treatment of osteosarcoma. Curr Opin Pediatr 2016; 28(1): 26-33, doi: 10.1097/MOP.0000000000000298, indexed in Pubmed: 26626558

88. Bousquet M, Noirot $\mathrm{C}$, Accadbled F, et al. Whole-exome sequencing in osteosarcoma reveals important heterogeneity of genetic alterations. Annals of Oncology. 2016; 27(4): 738-744, doi: 10.1093/annonc/maw009

89. Chen X. Bahrami A, Pappo A, et al. Recurrent Somatic Structura Variations Contribute to Tumorigenesis in Pediatric Osteosarcoma Cell Reports. 2014; 7(1): 104-112, doi: 10.1016/j.celrep.2014.03.003
90. Kovac M, Blattmann C, Ribi S, et al. Exome sequencing of osteosarcoma reveals mutation signatures reminiscent of BRCA deficiency. Nat Commun. 2015; 6: 1-9, doi: 10.1038/ncomms9940.

91. Lindsey BA, Markel JE, Kleinerman ES. Osteosarcoma Overview. Rheumatol Ther. 2017: 4(1): 25-43, doi: 10.1007/s40744-016-0050-2, indexed in Pubmed: 27933467.

92. Ho XD, Phung P, Q Le V, et al. Whole transcriptome analysis identifies differentially regulated networks between osteosarcoma and normal bone samples. Exp Biol Med (Maywood). 2017; 242(18): 1802-1811, doi: 10.1177/1535370217736512, indexed in Pubmed: 29050494

93. Zhou S, Wang B. Hu J, et al miR-421 is a diagnostic and prognostic marker in patients with osteosarcoma. Tumour Biol. 2016; 37(7): $9001-$ 9007, doi: 10.1007/s13277-015-4578-5, indexed in Pubmed: 26758431.

94. Kushlinskii NE, Fridman MV, Braga EA. Molecular Mechanisms and microRNAs in Osteosarcoma Pathogenesis. Biochemistry (Mosc). 2016; 81(4): 315-328, doi: 10.1134/S0006297916040027, indexed in Pubmed: 27293089.

95. de Carvalho IN, de Freitas RM, Vargas FR. Translating microRNAs into biomarkers: What is new for pediatric cancer? Med Oncol. 2016; 33(5): 49, doi: 10.1007/s12032-016-0766-4, indexed in Pubmed: 27085875.

96. Chaiyawat P, Settakorn J, Sangsin A, et al. Exploring targeted therapy of osteosarcoma using proteomics data. Onco Targets Ther. 2017; 10: 565-577, doi: 10.2147/OTT.S119993, indexed in Pubmed: 28203090.

97. Kim MJ, Cho KJ, Ayala AG, et al. Chondrosarcoma: with updates on molecular genetics. Sarcoma. 2011: 2011: 1-15, doi: 10.1155/2011/405437, indexed in Pubmed: 21403832

98. Sakamoto A. The molecular pathogenesis of dedifferentiated chondrosarcoma. Indian J Orthop. 2014; 48(3): 262-265, doi: 10.4103/00195413.132506, indexed in Pubmed: 24932031.

99. Polychronidou G, Karavasilis V, Pollack SM, et al. Novel therapeutic approaches in chondrosarcoma. Future Oncol. 2017; 13(7): 637-648, doi: 10.2217/fon-2016-0226, indexed in Pubmed: 28133974

100. Perez J, Decouvelaere AV, Pointecouteau T, et al. Inhibition of chondrosarcoma growth by mTOR inhibitor in an in vivo syngeneic rat model. PLoS One. 2012; 7(6): e32458, doi: 10.1371/journal.pone.0032458, indexed in Pubmed: 22761648.

101. Kim HK, Kim SY, Lee SuJ, et al. BEZ235 (PIK3/mTOR inhibitor) Overcomes Pazopanib Resistance in Patient-Derived Refractory Soft Tissue Sarcoma Cells. Transl Oncol. 2016; 9(3): 197-202, doi: 10.1016/j. tranon.2016.03.008, indexed in Pubmed: 27267837

102. Lugowska I, Teterycz P, Mikula M, et al. IDH1/2 Mutations Predict Shorter Survival in Chondrosarcoma. J Cancer. 2018; 9(6): 998-1005, doi: 10.7150/jca.22915, indexed in Pubmed: 29581779.

103. Schrage YM, Briaire-de Bruijn IH, de Miranda NF, et al. Kinome profiling of chondrosarcoma reveals SRC-pathway activity and dasatinib as option for treatment. Cancer Res. 2009; 69(15): 6216-6222, doi: 10.1158/0008-5472.CAN-08-4801, indexed in Pubmed: 19602594.

104. Schuetze SM, Wathen JK, Lucas DR, et al. SARC009: Phase 2 study of dasatinib in patients with previously treated, high-grade, advanced sarcoma. Cancer. 2016; 122(6): 868-874, doi: 10.1002/cncr.29858, indexed in Pubmed: 26710211.

105. Tarpey PS, Behjati S, Cooke SL, et al. Frequent mutation of the major cartilage collagen gene COL2A1 in chondrosarcoma. Nat Genet. 2013; 45(8): 923-926, doi: 10.1038/ng.2668, indexed in Pubmed: 23770606.

106. Campbell VT, Nadesan P, Ali SA, et al. Hedgehog pathway inhibition in chondrosarcoma using the smoothened inhibitor IPI-926 directly inhibits sarcoma cell growth. Mol Cancer Ther. 2014; 13(5): 1259-1269, doi: 10.1158/1535-7163.MCT-13-0731, indexed in Pubmed: 24634412

107. Wagner, AJ, Hohenberger P Okuno S, et al. Results from a Phase 2 Randomized, Placebo-Controlled, Double Blind Study of the Hedgehog Pathway Antagonist IPI-926 in Patients with Advanced Chondrosarcoma. New York, 2013

108. Italiano A Le Cesne A, Bellera C et al GDC-0449 in patients with advanced chondrosarcomas: a French Sarcoma Group/US and French National Cancer Institute Single-Arm Phase II Collaborative Study. Ann Oncol. 2013; 24(11): 2922-2926, doi: 10.1093/annonc/mdt391, indexed in Pubmed: 24170610. 